LA WRE NCE LIWEAMCAE NATIONAL LABOAATOAY

Methods for Calibrating

Basin-Wide Hydroacoustic

Propagation in the Indian

Ocean

Donna K. Blackman, Catherine de GrootHedlin, John A. Orcutt, Philip E. Harben, Doug B. Clark, Abelardo L. Ramirez

September 2004 
This document was prepared as an account of work sponsored by an agency of the United States Government. Neither the United States Government nor the University of California nor any of their employees, makes any warranty, express or implied, or assumes any legal liability or responsibility for the accuracy, completeness, or usefulness of any information, apparatus, product, or process disclosed, or represents that its use would not infringe privately owned rights. Reference herein to any specific commercial product, process, or service by trade name, trademark, manufacturer, or otherwise, does not necessarily constitute or imply its endorsement, recommendation, or favoring by the United States Government or the University of California. The views and opinions of authors expressed herein do not necessarily state or reflect those of the United States Government or the University of California, and shall not be used for advertising or product endorsement purposes.

This work was performed under the auspices of the U.S. Department of Energy by University of California, Lawrence Livermore National Laboratory under Contract W-7405Eng-48. 


\title{
METHODS FOR CALIBRATING BASIN-WIDE HYDROACOUSTIC PROPAGATION IN THE INDIAN OCEAN
}

\author{
FINAL REPORT, September 2004 \\ Donna K. Blackman ${ }^{1}$, Catherine de Groot-Hedlin ${ }^{1}$, John A. Orcutt ${ }^{1}$, \\ Philip E. Harben ${ }^{2}$, Doug B. Clarke², Abelardo L. Ramirez ${ }^{2}$ \\ University of California, San Diego, Scripps Institution of Oceanography ${ }^{1}$ \\ Lawrence Livermore National Laboratory ${ }^{2}$ \\ Sponsored by National Nuclear Security Administration \\ Office of Nonproliferation Research and Engineering, Office of Defense Nuclear Nonproliferation \\ Contract No. DE-FC03-01SF22356
}

\section{OBJECTIVE}

This collaborative project was designed to test and compare methods for achieving full ocean basin propagation of hydroacoustic signals in the $5-100 \mathrm{~Hz}$ frequency band. Plans for a systematic calibration of the International Monitoring System (IMS) for nuclear testing were under consideration in 2000/2001. The results from this project provide information to guide such planning for future ocean basin calibration work. Several acoustic source types were tested during two sea-going experiments and most were successful at generating signals that propagated hundreds to thousands of $\mathrm{km}$ to be recorded at the Indian Ocean IMS hydrophone stations. Development and numerical modeling of imploding glass sphere sources was one component of this testing. The intent was to design a relatively simple-to-use source that is not subject to restrictions that can limit use of explosive charges, but whose signal is large enough to propagate $100-1000$ 's $\mathrm{km}$ range. Analysis of IMS hydrophone data recording during the experiments was used to illustrate the extent of energy loss during signal propagation and to assess the accuracy with which the small acoustic sources could be located using methods typically employed for nuclear monitoring.

\section{RESEARCH ACCOMPLISHED}

Six types of acoustic sources were investigated for the project: a large airgun array; a single-sphere glass imploder; a 5-sphere glass imploder; a cylindrical, triggered imploder; $1.8 \mathrm{lb}$ explosive charges; and, an electro-acoustic projector. Two sea-going experiments were carried out and the acoustic sources were deployed along ship tracks that crossed the Indian Ocean, providing an excellent variety of sourcereceiver paths throughout the basin. Limits on the range of signal propagation for each source type have been established. The influence of noise level variation on signal detection at each Indian Ocean hydrophone station has been addressed. In a number of cases, numerical predictions of source output and transmission loss along the source-receiver path has been compared to observed levels.

Explanations for the differences between these predicted and observed levels are available in several cases but questions remain in others. The calibration signals were combined with earthquake events in a database for assessing hydroacoustic blockage in the Indian Ocean. 


\section{SUMMARY OF RESULTS}

The project as originally proposed was divided into three tasks. Task 1 covers the testing of acoustic sources for basin-wide propagation. Task 2 covers the analysis of recordings at the IMS hydrophones and characterization of source location uncertainties. Task 3 initially was to emphasize reflected acoustic waves in the Indian Ocean but the task was refocused on modeling and further development of the imploding glass sphere source. Investigators at Scripps Institution of Oceanography (SIO) took the lead for Task 1, both Lawrence Livermore National Lab. (LLNL) and SIO investigators contributed to Task 2, and LLNL completed all work done for Task 3.

\section{Task 1. Tests of Acoustic Source Types for Basin-Wide Propagation}

\subsection{Sea-Going Experiments}

The project benefited significantly from access to US academic fleet (UNOLS) vessels that happened to be operating near the Indian Ocean during the time we had funding. Blackman was able to work with the ship operators to arrange cost sharing between DOE and NSF, and ports that were optimal for this project as well as accommodating prior and subsequent scheduled ship users. As originally planned, the 2001 cruise aboard the R/V Ewing departed Seychelles and sailed to southwest Australia. The sources tested during this cruise were the large airgun array, glass-sphere implosions, and the MPL/SIO (Marine Physics Lab) imploding cylinder. The timing of the cruise was changed on short notice, due to 9/11 and other security issues, and this played a role in LLNL lack of participation in the sea-going work. In 2003, use of the R/V Melville was arranged for a track from Cape Town, South Africa, to northwestern Australia. This option offered, at the same cost, a significant improvement in coverage over the initial plan to use RRS Charles Darwin off Diego Garcia for a second cruise. As for the 2001 cruise, LLNL shipped glass spheres for use during the cruise; SIO and their associates on the project carried out the shipboard work. Source shots were SUS charges and glass sphere implosions.

The environmental review for marine mammal impacts differed between the cruises, largely due to the coincidence of when they occurred. In 2001, the ship operators followed a prior procedure (basically avoiding major migration routes and breeding grounds) for using a large airgun array in international waters. No problems with marine mammals were encountered. For the 2003 experiment, a DOE review of regulations, possible impacts, and mitigation plans was undertaken. An April 9, 2003, document provided to Ken Quitoriano, NNSA Livermore, contains a summary of the review and findings. No problems with marine mammals were encountered during the 2003 experiment.

A brief summary of results is presented in this Section. Figure 1 illustrates the source locations and summarizes the IMS detections. More detailed results are presented in Section 4 and in the listed publications. Source time and location tables are included as an Appendix; a typographical error contained in the 2003 source listing in a previous paper (Blackman et al., 2003) has been corrected.

\subsection{Large Airgun Array}

Signals from the R/V Ewing's full airgun array were recorded by IMS hydrophones at ranges up to and exceeding $4000 \mathrm{~km}$. However, the character of the seafloor in the vicinity of the airgun shots is a critical factor in how much energy is coupled into horizontally propagating waves that can travel within the oceanic sound channel- a key factor since the low attenuation there makes long-distance detection possible. Airgun shooting sites during the 2001 experiment were generally chosen to maximize the likelihood of downward propagation and scattering of the signal into the sound channel. Blockage by topographic features along the source-receiver path was also a factor in which shots were detected at the IMS stations. Signal-to noise ratios varied within the $5-100 \mathrm{~Hz}$ band, being influenced by near-source, along-path, and ambient noise conditions. In many cases, the differences in signal level at a given frequency was in line with first-order models of transmission loss but in a few cases scattering due to near-source bathymetric roughness probably contributed to the mismatch in predicted versus observed signal levels (Blackman et al., 2004). 


\subsection{Imploding Spheres}

The LLNL triggered imploding glass sphere source (Harben et al., 2000) proved very successful in the 22-liter, single-sphere configuration, for detection at ranges up to $\sim 1000 \mathrm{~km}$. Single-spheres triggered at $\sim 700 \mathrm{~m}$ depth were consistently detected within this range and the near-source signal had short duration and was quite repeatable. The five-sphere configuration (Harben and Boro, 2001) produced signals detected at full-basin ranges (up to $4400 \mathrm{~km}$, Blackman et al., 2004) but degradation of the frame after the first few uses resulted in decreasing effectiveness with time (Blackman et al., 2003). A new, linear design is under development to address this concern for the multi-sphere source (Harben et al., 2004).

\subsection{MPL/SIO Imploding Cylinder}

The 20-liter, cylindrical configuration of the MPL/SIO imploder (Sauter and Dorman, 2003) produces a signal whose level in the $100-200 \mathrm{~Hz}$ band that is 5-10 dB lower than the single glass sphere signal. We were not able to detect any of the imploder shots in the IMS hydrophone data.

\subsection{SUS Charges}

Use of the 1.8 lb SUS (Signals Underwater Sound) charges required notable pre-cruise efforts to make sure that all requirements for transport, handling, and storage of hazardous material were met. However, having done this for the 2003 cruise we are now in a good position to relatively easily address similar issues for any future work. Participation by US navy civilian personnel was key to our success for the cruise. Shipboard operations for the SUS are, by far, the simplest and least sensitive to sea conditions of all the sources tested for this project. Source depth uncertainty is documented by prior US Navy tests and is within the range that is useful for nuclear explosion monitoring research. Almost all the SUS charges that fired were detected at an IMS station. Differences in the SNR observed for source depths of 610 versus $915 \mathrm{~m}$ were not consistent throughout the experiment. In addition, the frequency content of the SUS arrivals did not consistently reflect the higher bubble pulse frequency of the deeper charges. Details of topographic variability along the different source-receiver paths can explain these inconsistencies since the losses at the seafloor interface vary with depth and roughness.

\subsection{UW/APL Electro-Acoustic Source- the HX554}

Jim Mercer at University of Washington's Applied Physics Lab (UW/APL) led the work with the electro-acoustic source for this project. As part of the budget negotiation for the project, it was decided that the HLF-1A was not a viable option so we pursued work with the pre-existing ATOC (Acoustic Thermometry of Ocean Climate) source. The modifications to that previously existing system and participation of the UW/APL group on the $2003 \mathrm{R} / \mathrm{V}$ Melville cruise were funded as a subcontract with SIO. The ATOC system was known to produce fully characterized signals in the $40-100 \mathrm{~Hz}$ range that are detected by hydrophones at ranges of a few thousand $\mathrm{km}$. The system operated very reliably during earlier ATOC work. Modifications for use of the originally moored system for use from a ship deck entailed a number of changes. Unfortunately, a very minor problem with a pressurization line not being adequately attached led to major failure during the 2003 experiment. Subsequently, UW/APL rebuilt the parts that failed due to lack of pressurization and the system is now operational, The new configuration and signal characteristics are described in Section 4.5, in an extract of Mercer's May 2004 field test report. 


\section{Task 2. Analysis of IMS Hydrophone Data- Source Detection and Location}

\subsection{Detections and signal character}

Near-real-time access to the Diego Garcia (H08) and Cape Leeuwin (H01) data was arranged by Orcutt and de-Groot Hedlin for both the 2001 and 2003 cruise. These data are archived on the mass storage unit at SIO, access is currently restricted to de Groot-Hedlin and Blackman. Sections of the Crozet IMS data (H04) were kindly provided by John Newton, CTBTO, for time windows covering the 2003 source tests. Blackman retains these data at SIO. LLNL investigators also have the data from Diego Garcia and Cape Leeuwin for both experiments. Near-source recordings provided waveform data (Harben et al., 2002; Blackman et al., 2004) for comparison to IMS recordings of the 2001 sources (airgun array, single- and five-sphere glass implosions). In 2003, the near-source hydrophone was designed for use with the HX-554. It was overwhelmed by the SUS and glass-sphere signals; only origin time was obtained from these near-source data.

Methodology for assessing signal detection differed somewhat for LLNL (Harben and Ramirez) and SIO (de Groot-Hedlin and Blackman) investigators although both applied fairly standard processing techniques, using time and frequency domain analyses. The results for the SIO and LLNL analysis agree in almost all cases. The frequency content of IMS arrivals was variable for individual sources as well as between sources and between source-receiver paths (Harben et al., 2002; Blackman et al., 2003; Blackman et al., 2004). The imploding spheres were recorded with good SNR at frequencies above 40 Hz. The airgun array signals retained high SNR in the 5-15 Hz bands for some near-source seafloor conditions and some along-path topography (Blackman et al., 2004); in other cases, the airgun array signal only had high SNR in the 30-60 Hz band. The SUS signals recorded at the IMS hydrophones generally had high SNR in the 30-100 Hz band; only the shot at site A11 contained lower frequency energy as well.

\subsection{Source Location Uncertainties}

The arrival time of the signals at the IMS stations was always found to be within a few seconds of the time predicted for propagation at $1.49 \mathrm{~km} / \mathrm{s}$ along a geodesic path. The azimuth of the arrival, determined from either cross correlation of the wave forms or comparison of arrival times and an assumption of planar wave propagation between sensors, was within a degree or two of that expected in cases where SNR was high (Blackman et al, 2003; 2004). At the relevant source-receiver ranges, this translates into a location uncertainty of $5-15 \mathrm{~km}$. For less strong signals or when the arrival duration was longer than 1-2 s, back azimuth estimates were in error by as much as $30^{\circ}$ (Blackman et al., 2004).

None of the source signals generated by this project were strong enough to produce reflections off topographic slopes that contained enough energy to be detected at the IMS hydrophones. To date, earthquakes are the best sources for studying the patterns of reflected waves in the Indian Ocean.

\section{Task 3. Glass Sphere Source Development and Implosion Modeling}

\subsection{Source Instrumentation Development}

The imploding glass sphere system began as a single 22-litre sphere with a smashing system based on a calibrated rupture disk failing at a specific depth, driving a piston and ram into the glass sphere to cause catastrophic failure. This system had been tested and proved reliable with signals detected at ranges up to $1000 \mathrm{~km}$. During this project, the one sphere system was redesigned to a 5-sphere system. The 5-

sphere system employs the same smashing system to initiate only one of the five spheres, relying on the 
other spheres to fail sympathetically. The 5 spheres are held together in a cluster. The disadvantage of this geometry is that it is not axially symmetric and hence the source waveform showed poor repeatability. This system was extensively tested during the 2001 and 2003 cruises and although initiation proved reliable, repeated uses caused cumulative damage to the containing frame. The 5sphere system did produce signals recorded at ranges as far as $4400 \mathrm{~km}$. A containing geometry that preserves the 5-sphere source strength, and is repeatable and durable, has been developed since the 2003 cruise. This system allows any number of spheres to be contained in a linear structure with the initiating sphere and smashing system at the bottom of the lowered assembly. A prototype system has been developed and awaits testing at sea.

\subsection{Source modeling}

The glass sphere implosion source was modeled extensively during the course of this project. The modeling objectives were to understand details of the evolution of the shock wave for the purpose of long-range signal level prediction and optimization of the implosion system design. Most of the modeling effort focused on the evolution of the shock wave and prediction of the source waveform at 1 meter from the implosion point. The code used for this modeling was CALE ( $\underline{C}$-code, Arbitrary Lagrangian, Eulerian), a hydrodynamics modeling tool developed at LLNL (Hagelberg et. al., 2003). Successively more complex and realistic modeling of the experimental conditions produced modeled waveform features that eventually matched most of the recorded waveform features. The simplest model was an air-filled void at implosion depth (700 meters). The dynamics of the collapse produced a waveform matching the essential features of the experimentally recorded waveform (pre-shock rarefaction followed by a high overpressure spike and a bubble pulse). Matching the modeled peak pressure with the experimental peak pressure required that the air pressure within the sphere be $1 / 6$ that of atmospheric pressure. This proved consistent with the glass blowing and sealing process. A clear nonlinear inverse relationship between initial air pressure within the sphere and peak shock pressure was demonstrated in the modeling. Although the glass crushing and breaking phenomena could not be modeled, a liquid glass shell surrounding the air-filled void and matching the experiment in glass density and mass was modeled. Including the glass produced a trailing shoulder on the shock wave pulse and afterwards a small amplitude, short duration pulse that qualitatively agrees with the experimental data. The only feature the modeling failed to predict correctly was the pulse width of the shock wave, the model producing consistently narrower pulses. This could be because of the glass crushing -which we could not model- or could in part reflect an instrument response to the very rapid rise by the hydrophone used to record the signals. The most complex model included the glass shell and accounted for the finite time it takes for the fracturing of the glass (initiated at one pole of the sphere) to propagate around the sphere. This model showed an asymmetric collapse and strong directionality in the shock wave with the largest pressures opposite the initiation point. This prediction has implications for design and use of these sources experimentally but remains untested. 


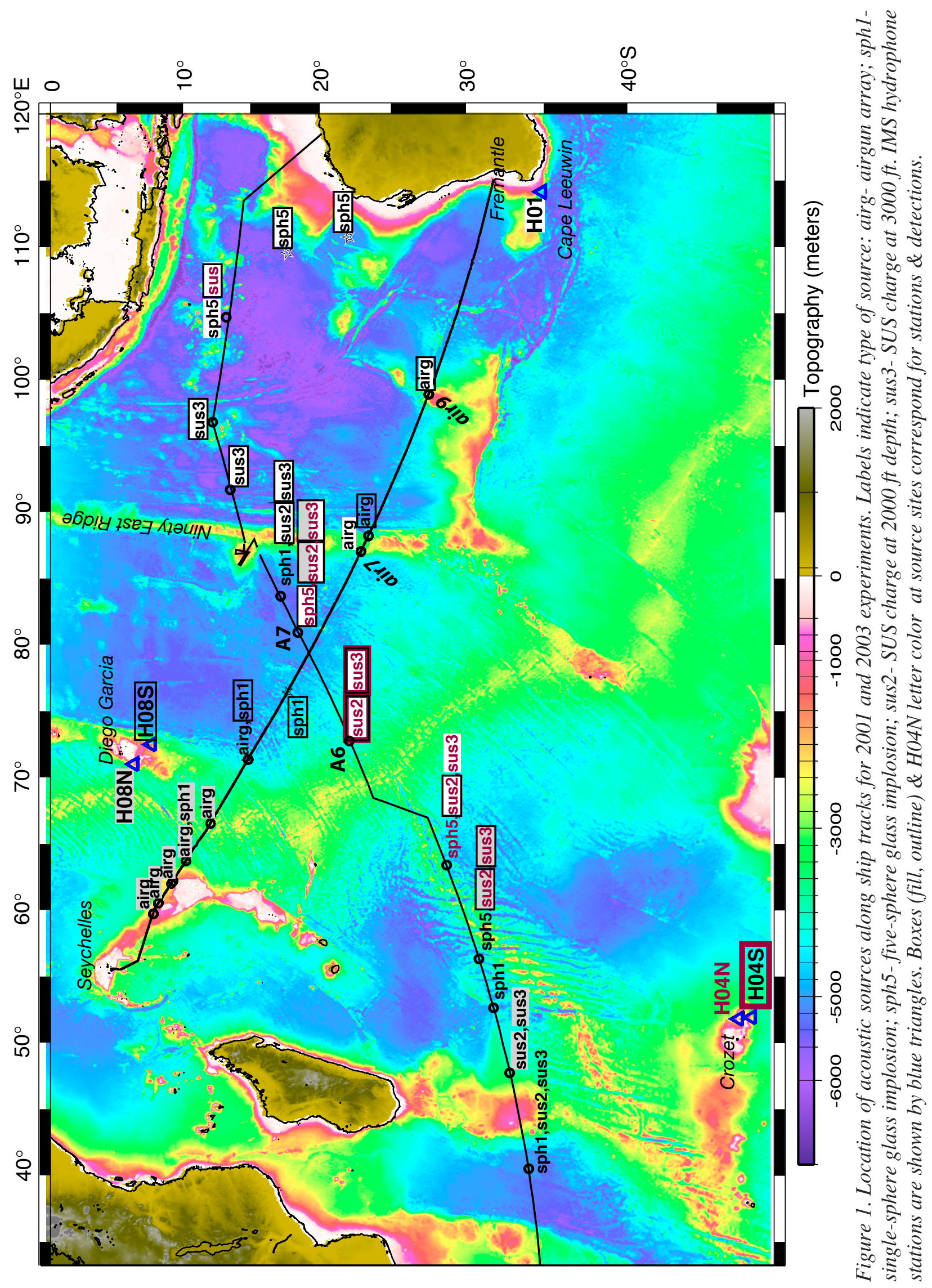




\section{DETAILS OF TECHNICAL RESULTS}

\subsection{Large Airgun Array Shots}

The R/V Ewing array of 20 airguns had a total volume of 8465 cubic inches $\left(0.139 \mathrm{~m}^{3}\right)$. The peak level of the airgun array signal was measured at 230-240 dB re $1 \mu \mathrm{Pa}$ (adjusted to 1 meter range) in the $5 \sim 60 \mathrm{~Hz}$ range (Fig. 2). The duration of the airgun array pulse is about $12 \mathrm{~ms}$. Source depth is $9-12 \mathrm{~m}$. Shot trigger times are generally accurate to a millisecond. Shot locations generally are accurate to about $10 \mathrm{~m}$; loss of high resolution (P Code) GPS during the last shooting period resulted in greater uncertainty, $\sim 50 \mathrm{~m}$.

Corrections for the difference in location between the GPS receiver and the center of the airgun array are incorporated in the airgun shot locations listed in Table I.
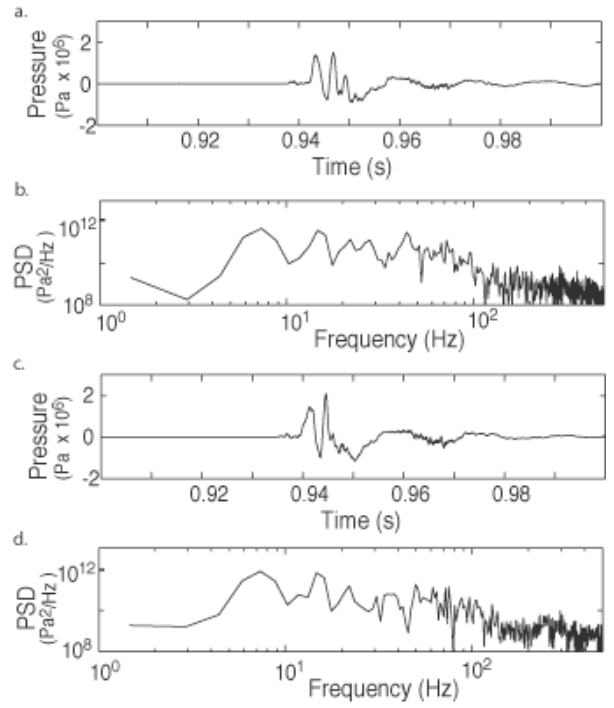

Figure 2. Time series $(a \& c)$ and power spectral density $(b \quad \& \quad d)$ of two representative airgun array shots as recorded on the near-source hydrophone. Levels are corrected to a distance of 1 meter from the source.

Seafloor topography in the vicinity of each shot controls the efficiency of coupling the airgun energy into a nearly horizontally propagating wave that is guided long distance by the sound channel. Details of the local depth, slope, and seafloor roughness (Blackman et al., 2004) all contribute to this process of transferring energy from the dominantly down-going pulse into horizontally traveling rays.
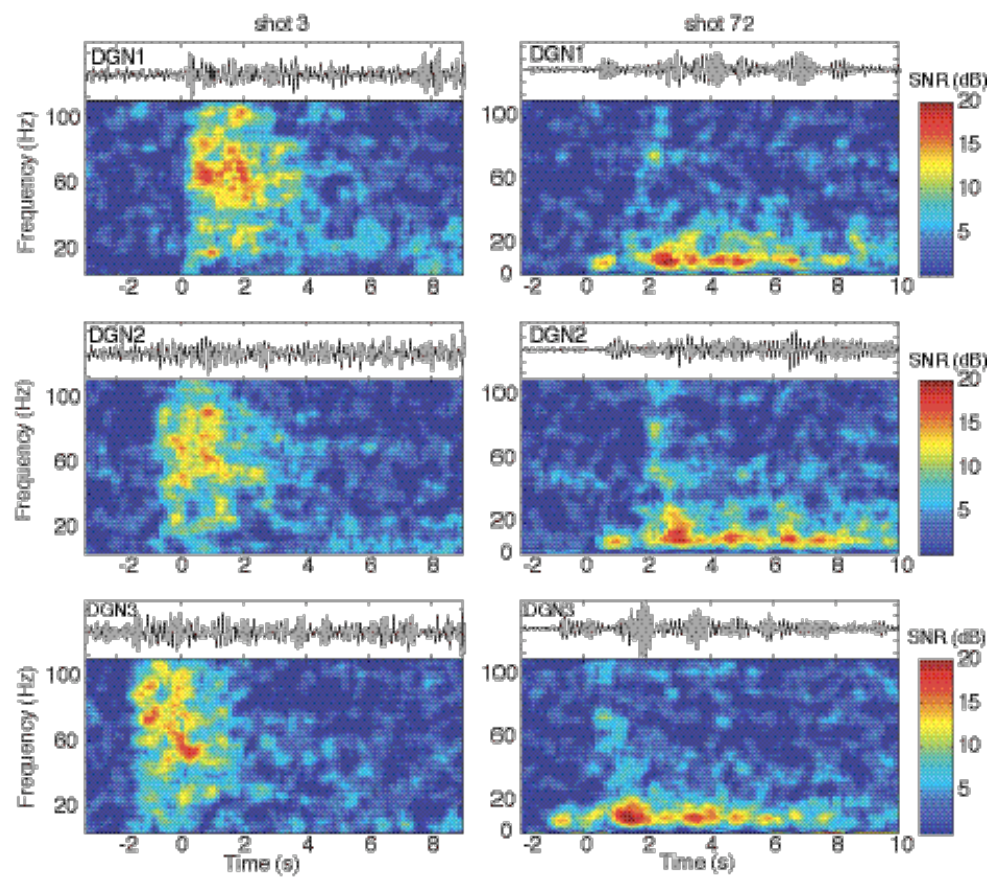

Figure 3. Examples of individual airgun array shot recordings at the three hydrophones of H08N. Panels on left show shot 3 from airl site. Panels on right show shot 72 from air 5 site. Unfiltered times series data are plotted above corresponding spectragram in each panel. The spectragrams show signal-to-noise ratio as a function of time and frequency. The spectrum of the signal for each 1-second window is divided by the noise spectrum computed for a 5-second window immediately prior to the shot. Overlap between windows is $\sim 0.9$ second. 
The signal recorded for our series of airgun shooting sites varied as a function of both receiver and source location. Propagation to H08S was blocked for the first 4 airgun sites. We expected H01 to be blocked from the first site and then from some of the subsequent 5 sites by the Ninety East RiH08e (Fig. 1). Propagation from shooting last 3 sites (air6-air9, Table 1) to H08N was also blocked.

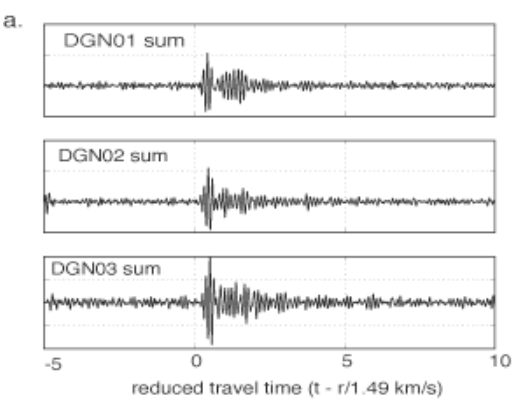

b.

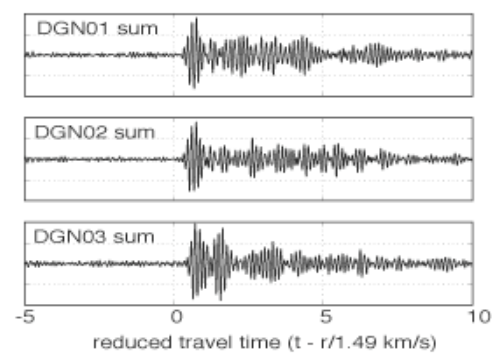

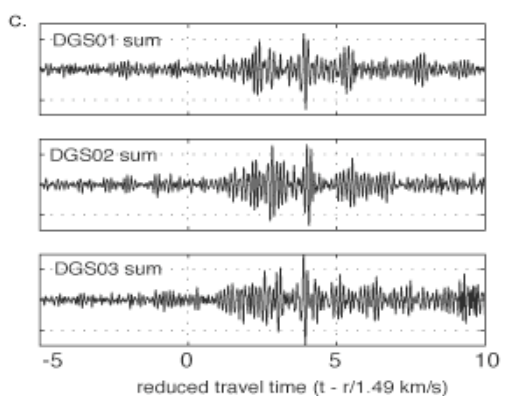

d.

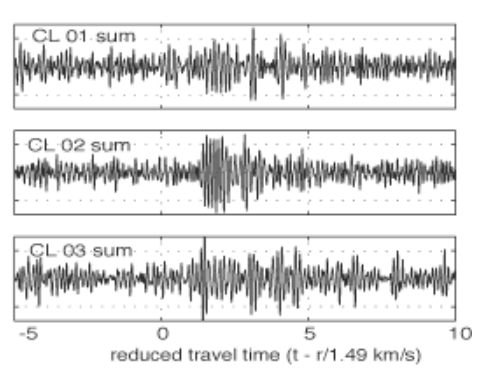

Figure 4. Examples of airgun array shots recorded at the IMS hydrophones. All shots at each site are stacked after moveout correction. Sections are bandpass filtered 5-10 $\mathrm{Hz}$ and time zero corresponds to propagation velocity of $1.49 \mathrm{~km} / \mathrm{s}$ for each source-receiver range, $r$. (a) air2 shots at each of the H08N hydrophones (b) air5 shots at the 3 HOSN hydrophones, (c) air9 shots at each HOSS hydrophone (d) air9 shots at each $\mathrm{HOI}$ hydrophone.

Figures 3 and 4 illustrate the difference in arrival character between airgun shooting sites and between receiving stations. In some cases, the source-receiver pairs have sufficiently high SNR that the individual shots are visible in filtered sections. In other cases, stacking of all shots for a given site, following moveout correction, is required to improve the SNR. Stacking is ineffective for frequencies greater than $30 \mathrm{~Hz}$; we infer that in this band acoustic energy is strongly influenced by details of the seafloor topography, which changes somewhat as the ship progresses along the track. The recordings of air 2 shots have high SNR in the $5-10 \mathrm{~Hz}$ range and the time series data show that the wavetrain following the initial pulse is short ( 2 seconds; Fig. 4a). The air5 shots have high SNR in the $5-40 \mathrm{~Hz}$ band (Fig. $3 \mathrm{~b}$ ) and the wave duration after the main pulse exceeds 5 seconds in the $5-10 \mathrm{~Hz}$ band (Fig. $4 \mathrm{~b}$ ).

Both H08S and H01 recorded the shots for air9 (Figure 4c-d). The signal recorded at H08S is clearly visible at a whole-basin-scale source-receiver range of about $4825 \mathrm{~km}$. In the $40-60 \mathrm{~Hz}$ range, H08S recordings exceed the noise level significantly but the waveforms are not very similar. In the $5-10 \mathrm{~Hz}$ band, the stacked H08S waveforms show a narrow peak about 3 seconds from the onset of the arrival (Fig. 4c). At H01, the record contains significant energy in a broader frequency band -- 30-60 Hz. These were the only shots that were clearly visible in the VLF band at Cape Leeuwin, at a range of 1665 kilometers. Blockage of air 8 shots is not known to be significant and H01 noise levels during those shots were similar to levels during the air9 shots. It is not clear why these shots were not observed. The air 7 shots occurred during a somewhat noisier period (Blackman et al., 2004) and over the west-dipping slope of the Ninety East Ridge that was not as favorable for entrainment in the sound channel in the direction of H01. However, some energy did propagate the full range.

\subsection{Glass-Sphere Implosions}

The single sphere produces a signal (Fig. 5a) with an initial, relatively low frequency rarefactional pulse that corresponds to the inrush of water caused by failure of the glass container. Convergence at the sphere center is the instant of shock wave formation, giving rise to the spike that dominates the record; a small 
bubble pulse follows. The record in Fig. 5b shows a composite collapse of 5 spheres during the initial rarefactional pulse of the wavetrain. Short duration features riding on the longer rarefactional pulse are consistent for both of the 5-sphere source waveforms we recorded but the reasons for these features are not clear. The shock wave from the first implosion is visible, overlain and followed by the implosion shock waves from the other spheres. The number and pattern of these spikes were significantly different for the two 5-sphere source records. The time differences are consistent with failure caused by fracture propagation from sphere to sphere but are not consistent with a shock wave driven by collapse of adjacent spheres from the first implosion. The imploding glass spheres achieve maximum levels in the $300-500 \mathrm{~Hz}$ range of 250-270 dB re $1 \mu \mathrm{Pa}$, corrected back to 1 meter from the source, but the level at other frequencies is much reduced. At the source, the pulse is about $6 \mathrm{~ms}$ long.

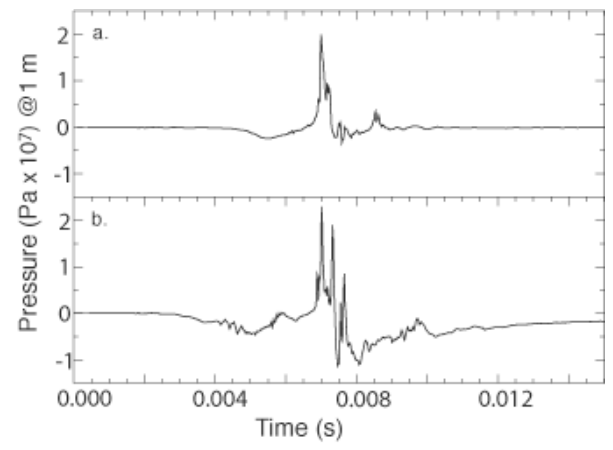

Five of the six successful imploding glass sphere shots in 2001 (Tables 3,4) were detected at IMS hydrophone stations. All detected shots had source depth $\sim 680$ meters; a $320 \mathrm{~m}$ deep implosion ( $s p h 2$ ) fired at the same location as a deeper shot (sph3) was not detected. Ranges between the single-sphere shots and the receiver were 800$1200 \mathrm{~km}$. The single sphere signal level rises above the noise level for frequencies greater than about $40 \mathrm{~Hz}$ (Fig. 6). The duration of the received signal is almost $400 \mathrm{~ms}$ longer than the near-source pulse duration. The bandwidth of the 5-sphere arrivals is similar to that of the single-sphere recordings. Peak amplitudes are not right at the onset of the arrival but are consistently in front of the center of the envelope whose length is about 1 second (Fig. 7).

Figure 6. Spectragrams of the signal from single-glass-sphere implosion sph 1(Table 3) recorded at H08N. Unfiltered time sections are above each spectragram (instrument counts, grayshade, show relative level of signal and noise). Time zero is travel-time at $1.49 \mathrm{~km} / \mathrm{s}$ for range of $798 \mathrm{~km}$ to $\mathrm{H} 08 \mathrm{NO}$.
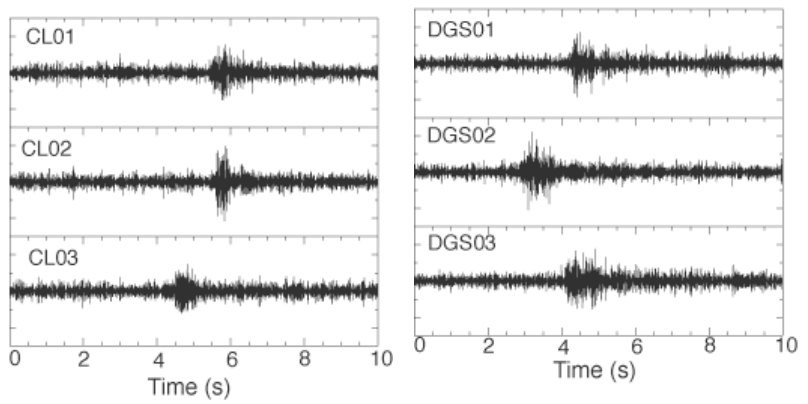

SIO/LLNL Final Report: Indian Ocean calibration methods
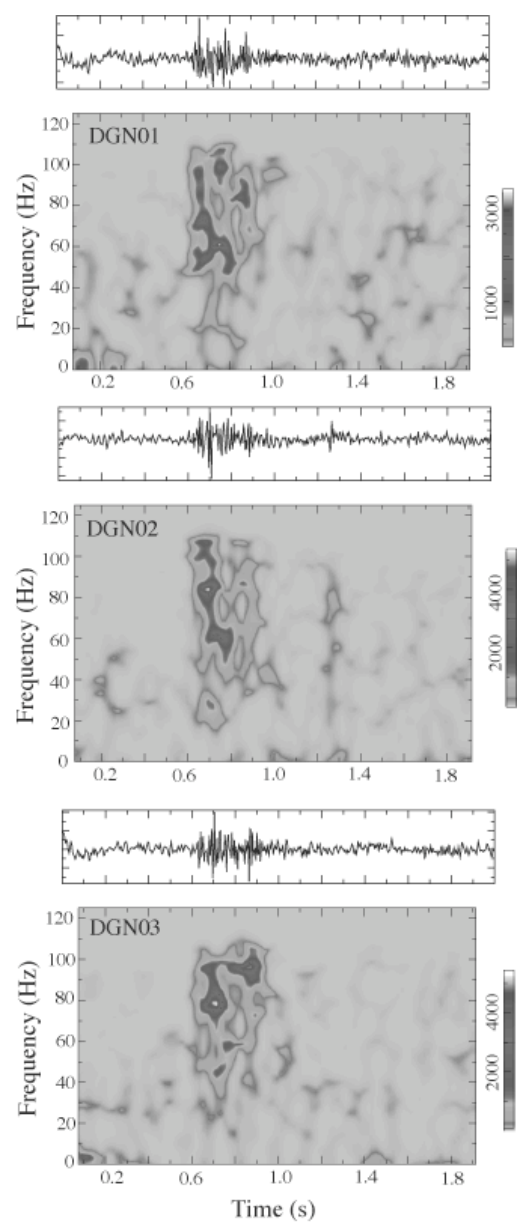

Figure 7. Five-sphere signal (sph7) high pass filtered, cut at $40 \mathrm{~Hz}$. Time zero corresponds to travel time at $1.49 \mathrm{~km} / \mathrm{s}$ for range of 4396 and $1465 \mathrm{~km}$ to H08SO1 and H0101, respectively. 


\subsection{MPL/SIO Imploding Cylinder}

The cylindrical configuration of the MPL/SIO imploder [Sauter et al., 1996] operates by using the hydrostatic pressure at depth to mechanically open an empty 20-liter cylinder upon electrical command. Displaced water fills the cylinder, generating an acoustic signal. The instrument is lowered on a .322 CTD cable to the firing depth, indicated by the winch wire readout, and then triggered from the ships' lab. The imploder was deployed at 7 stations (Table 2) and firing was successful at five of these. The source is quite repeatable and has 3 separate arrivals (Figure 8). Arrival 1 is generated by the release pin as it strikes the brass manifold cap, after release. Arrival 2 is generated when water finishes filling the $1 \mathrm{st}$ stage prior to piston movement. The resulting pressure on the inner face forces the piston to move, pulling the endcap off of the main cylinder. The high frequency signal that precedes arrival 3 for 6 milliseconds is most likely caused by turbulent filling of the main cylinder. Arrival 3, the largest, is generated when the cylinder is completely filled. Its amplitude is consistently about $1 \times 10^{6} \mathrm{~Pa}$ re $1 \mathrm{~m}$.

Apparently the imploder's signal is too small to be detected above background noise at ranges of a few hundred kms. We were not able to detect any of the imploder shots in the IMS hydrophone data.
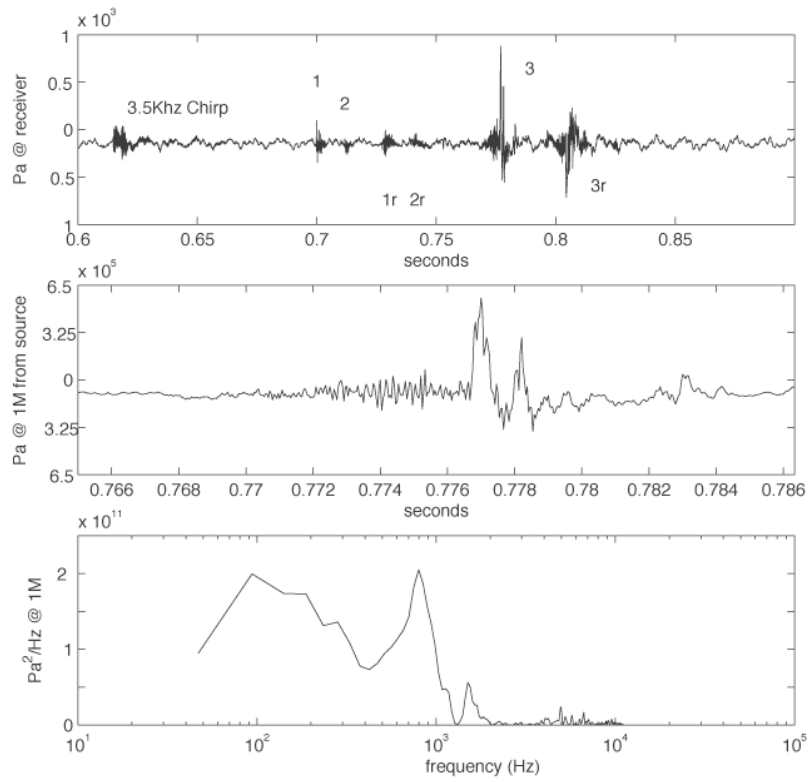

Figure 8. The MPL/SIO imploder signal for a 1000 meter deep shot (a) Full time series on near-source hydrophone (b) Main arrival corrected for geometric propagation loss between the source and receiver. (c) Power Spectral Density of direct arrival shown in $b$.

\subsection{SUS Charges}

Almost all SUS shots were detected at the IMS stations. Two charges did not trigger successfully, and two that did fire but were not detected were closest to Crozet (site A1, Table 5) but those hydrophones were experiencing very high noise conditions at the time. From four sites, all three Indian Ocean IMS hydrophone stations recorded the SUS signals. Figures 9-11 illustrate the character of the signal recorded at the IMS hydrophones.

Analysis of the SUS and 2003 glass sphere implosion signals was carried out by both SIO and LLNL and findings agreed in all but two cases; the LLNL analysis of the 2003 cruise are included in Appendix B. SIO typically used 1-s windows for spectral estimates of the signal character. A Hanning taper was applied prior to Fourier transform and power spectral density was computed. Sonograms showed changes in frequency content throughout the arrival as well as for pre- and post-event periods. In some cases, spectra were analyzed in terms of signal-to-noise ratio, obtained by dividing the signal spectra by pre-event noise spectra. If SNR exceeded $5 \mathrm{~dB}$ within a band that spanned at least $15 \mathrm{~Hz}$ within the 5- 
$100 \mathrm{~Hz}$ range, the signal was considered detected. LLNL spectral analysis assessed content for longer windows (generally 6-s). A detetection was classified as robust when: 1) the predicted and arrival times agreed within 20 secs, 2) The amplitude in the event spectra was clearly larger than the amplitude in the "noise" spectra, 3) The predicted and observed back azimuths were in approximate agreement (within 45 degrees of each other). For example, the plot on the right side of Figure 10 shows a robust detection where all three conditions were met. Additional results are presented in Appendix B..

The few cases where different results were obtained were: 1) The five-sphere implosion at site A11 was indicated as detected in the LLNL analysis where as SIO (and Australian colleagues monitoring the Cape Leeuwin data during the experiment) did not detect the signal. LLNL had a larger time allowance (20 s) and backazimuth tolerance $\left(45^{\circ}\right)$ so this may have accounted for the different result. 2) The two SUS charges at site A4 were detected at Diego Garcia, North, in the SIO analysis but not picked up using the LLNL method. This may be due to the shorter window used in the SIO processing, which indicated brief higher signal levels than the single, longer spectral estimate could.

a.
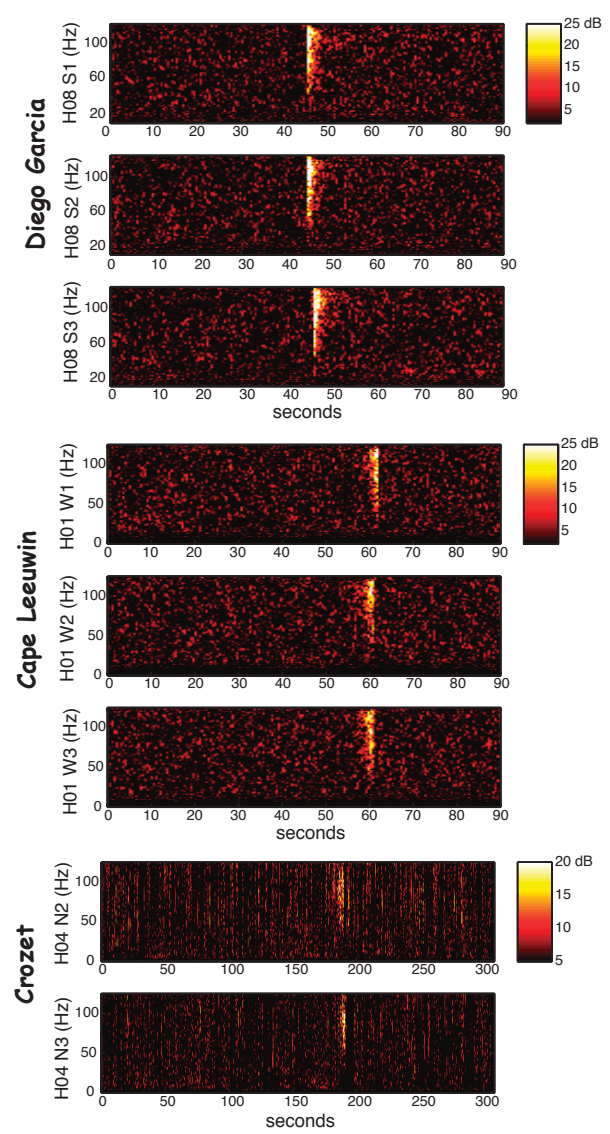

b.
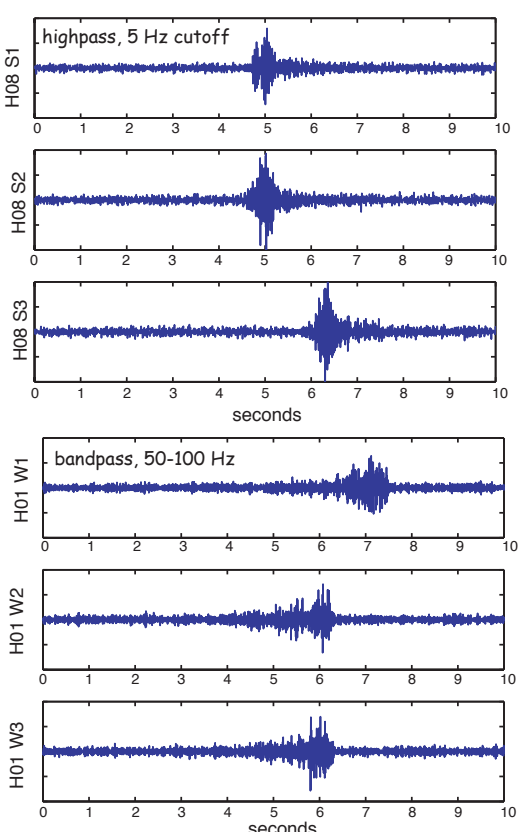

c.
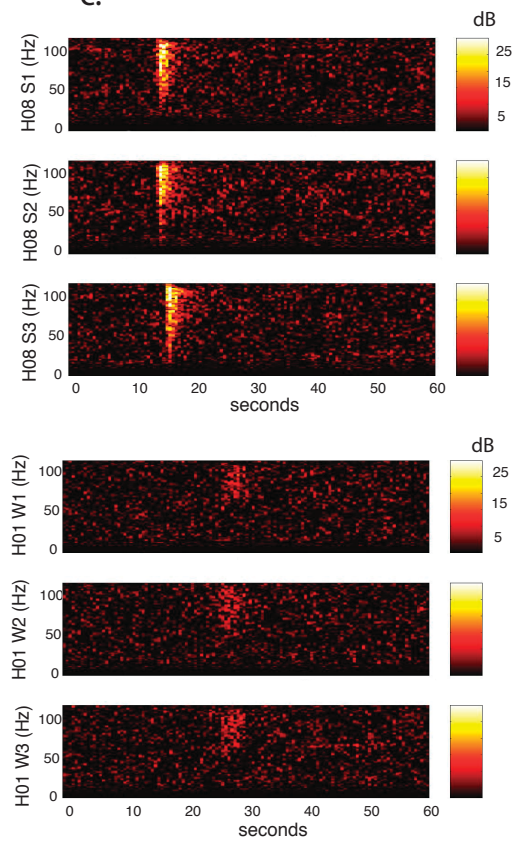

Figure 9. IMS recordings of SUS shots at site A6. a) Sonograms for charge detonated at $915 \mathrm{~m}$ depth. Mean (background) spectral level for each time period shown has been subtracted, as a function of frequency. b) Time series data for the $915 \mathrm{~m}$ shot. Note differences in position of peak amplitude within the envelope between the stations and sensors. c) De-meaned sonograms for $610 \mathrm{~m}$ deep charge. 

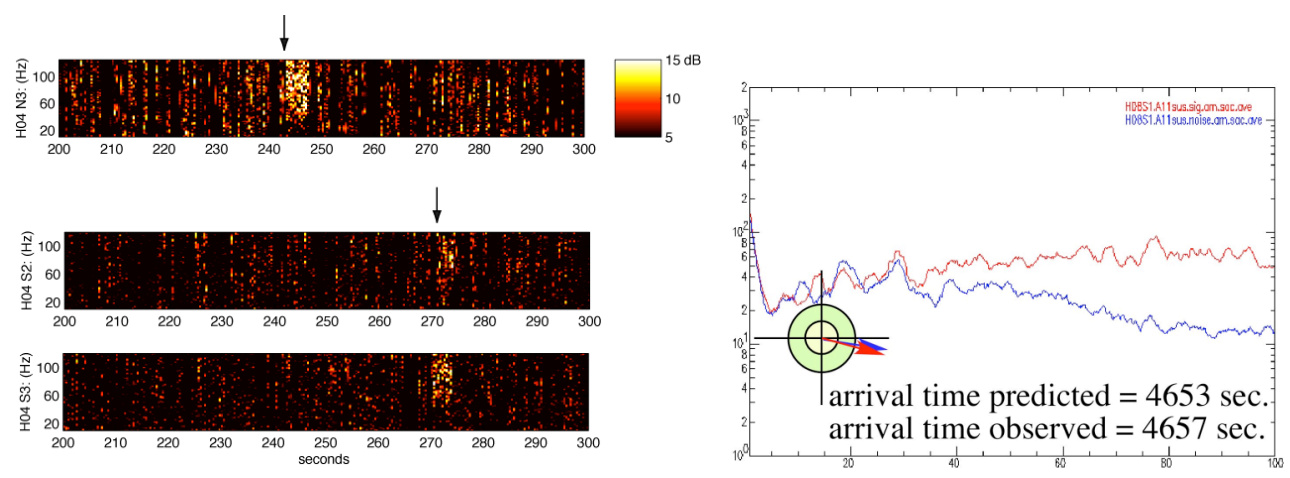

Figure 10. (left) Sonograms of SUS at site A8, $610 \mathrm{~m}$ depth, for Crozet. H04N, top, and H04S, bottom two panels. (right) Spectra of signal (red curve) and noise (blue curve) for SUS shot at site A11 recorded on H08S hydrophones. The arrows indicate the predicted and observed back azimuths.

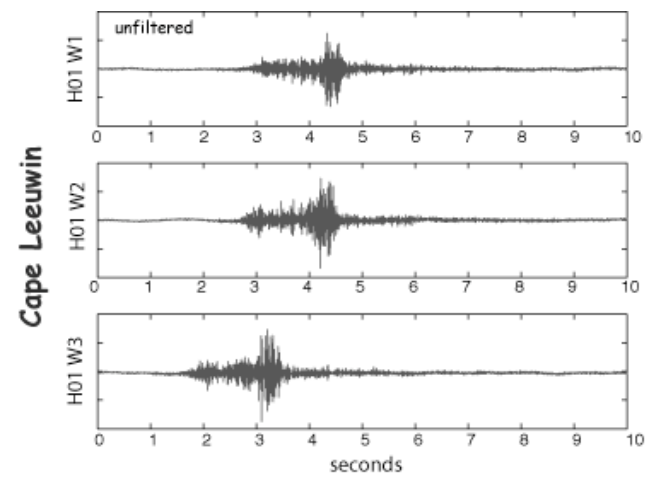

Figure 11. Signal from charge detonated at $915 \mathrm{~m}$ depth at site A11 (for details contact dblackman@ucsd.edu). All three IMS hydrophone stations recorded this shot. Source-receiver range is $6140 \mathrm{~km}$ to H04N, $3577 \mathrm{~km}$ to H08S, and $2595 \mathrm{~km}$ to H01. Cape Leeuwin arrivals contained significant energy at frequencies 10-120 Hz. Topographic stripping on the southern slope of Cocos-Keeling Island was significant.

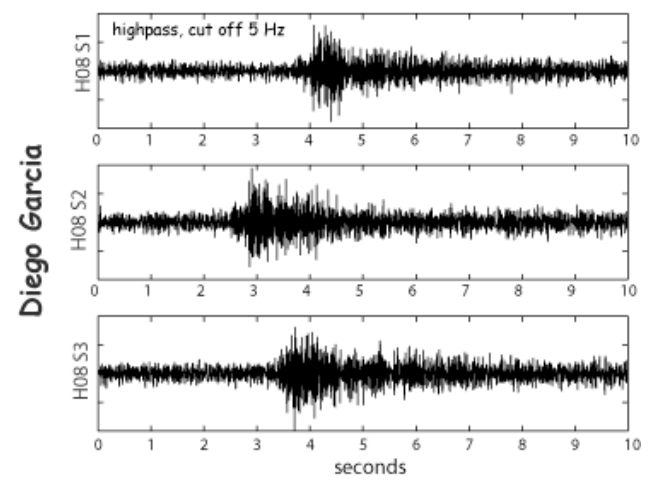

The recording at Diego Garcia contained most energy in the 60-100 Hz band and had reduced energy to frequencies as low as $30 \mathrm{~Hz}$. Duration of the arrival at the north arm of Crozet hydrophone station $(\mathrm{HO} 4 \mathrm{~N})$ was about 8 seconds, with energy spread evenly in the $40-100 \mathrm{~Hz}$ band.

\subsection{UW/APL Electro-Acoustic Source}

The acoustic source is one of the three Alliant-Tech HX-554 sources made for ATOC in 1994. The specific one that used is serial number 002 (Figure 12), the same one used during the Acoustic Engineering Test (AET) in 1994 off R/P FLIP. During that experiment the source was damaged (flooded upon the first recovery) and subsequently repaired and tested in Lake Washington and Puget Sound in June 1997. In 2003 it was modified for ship-suspended use (the outer boot was removed to reduce weight and a new frame was added) in the Indian Ocean as part of a CTBT project; the R/V Melville was also used for this cruise. At the start of that cruise, a failure in the air pressure compensation system caused a fracture in one of the ceramic bars of the transducer. The source was refurbished in 2003-2004 by removing the damaged ceramic from the circuit and thoroughly cleaning and testing all of the ceramic bars. Tests similar to the earlier ones in Lake Washington were repeated in April 2004. 

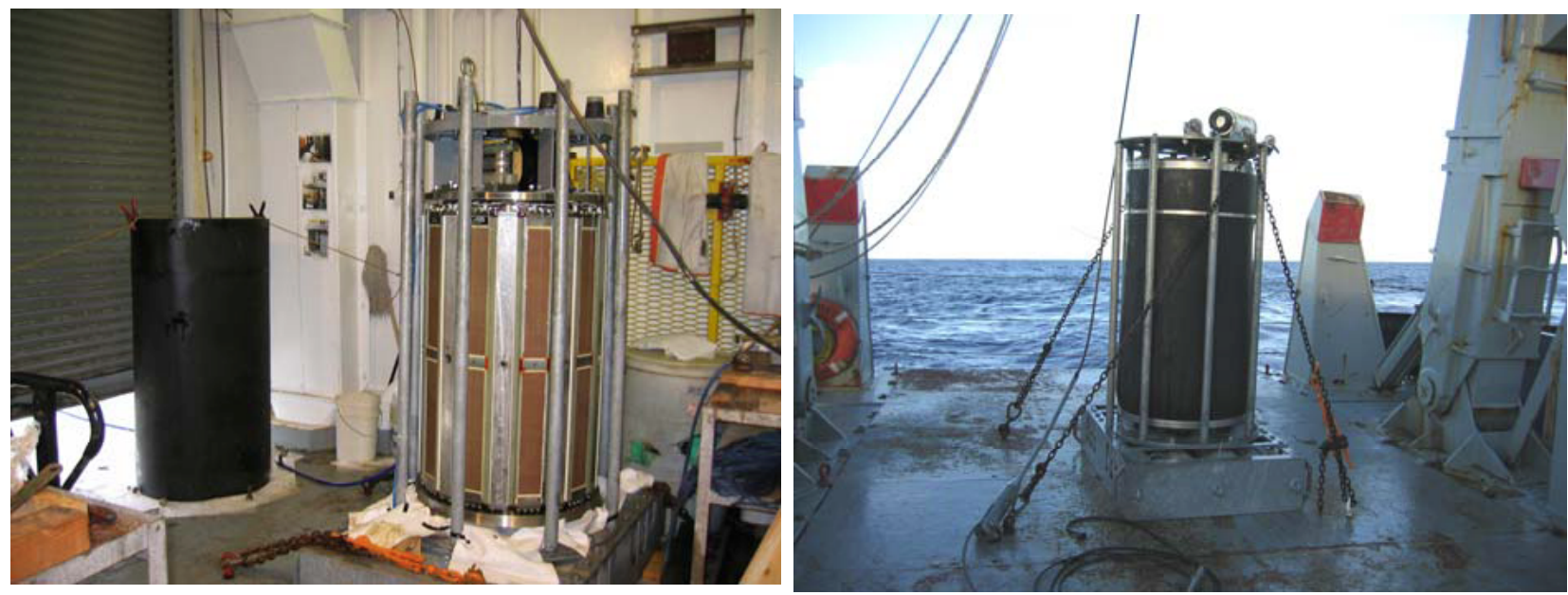

Figure12. The HX-554 acoustic source onboard the R/V Melville during 2003 cruise. (left) in the lab with the oil drained and boot set to left of the instrument; ceramic staves are visible. (right) tied down on the stern of the ship with the oil-filled boot on and mounted in its frame.

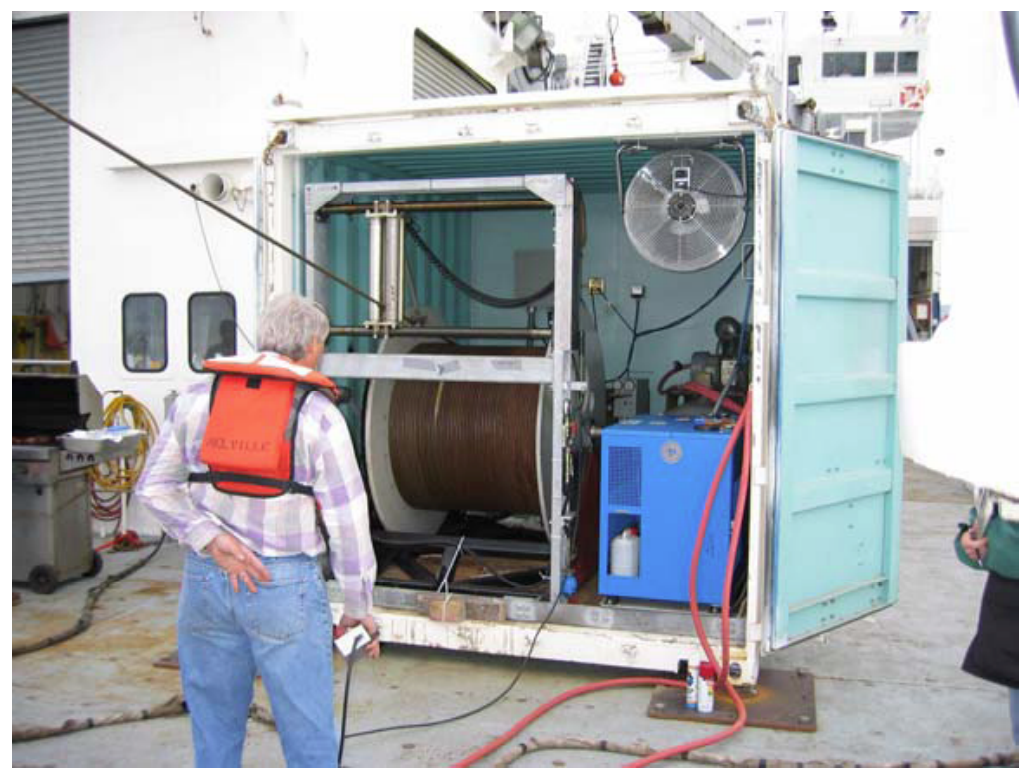

Figure 13. The winch and aft end of the 20-foot van for the HX-554 acoustic source, on the $R / V$ Melville stern during 2003 experiment. The control area is in the forward portion of the van, partitioned by the light blue wall visible behind the winch in this view.

A deep water (source depths $800 \mathrm{~m}$ and $300 \mathrm{~m}$ ) test was performed 20-23 May 2004 on the R/V New Horizon near San Clemente Island, California. This cruise provided a test of all parts of the acoustic source system, including the transducer, gas pressurization system, signal electronics, and the handling system. At a depth of $800 \mathrm{~m}, 75 \mathrm{~Hz}$ m-sequence (a code with variable length pulses) and $65 \mathrm{~Hz} \mathrm{CW}$ signals were transmitted at $260 \mathrm{~W}(195 \mathrm{~dB}$ re $1 \mu \mathrm{Pa}$ at $1 \mathrm{~m})$; a Prescription FM (PFM) signal was transmitted at $191.8 \mathrm{~dB}$ re $1 \mu \mathrm{Pa}$ at $1 \mathrm{~m}$. At $300 \mathrm{~m}$ depth, $75 \mathrm{~Hz}$ m-sequence signals were transmitted at $188 \mathrm{~dB}$ and $65 \mathrm{~Hz} \mathrm{CW}$ signals were transmitted at $195 \mathrm{~dB}$ re $1 \mu \mathrm{Pa}$ at $1 \mathrm{~m}$; the PFM signal was not transmitted. The maximum power transmitted for some of these signals was limited $(<195 \mathrm{~dB}$ re $1 \mu \mathrm{Pa}$ at $1 \mathrm{~m}$ ) because of uncertainty about permissible maximum voltage stress and mechanical bender bar stress levels. We are modifying our numerical model of the transducer based upon the transmit voltage response (TVR) measurements at 300 and $800 \mathrm{~m}$. In addition, we have met with AlliantTech engineers 
who were involved with the initial development of this transducer. We expect the outcome of these efforts to be a better understanding of the appropriate limits for the critical parameters of maximum voltage and maximum stress. We plan to complete the calibration measurements at our first station during a September, 2004, cruise. Present modeling efforts indicate we should be able to transmit all three signal types with source levels at or close to $195 \mathrm{~dB}$ at $350 \mathrm{~m}$ (slightly deeper) and $800 \mathrm{~m}$. The source is now held in a frame with the air bottles under it. The frame is $2.03 \mathrm{~m}$ (80 in) tall and the rectangular base is $1.02 \mathrm{~m}$ by $1.42 \mathrm{~m}$ (40 in by $56 \mathrm{in}$ ). The combined weight is $2410 \mathrm{~kg}$ (5300 lbs) in air and approximately $1820 \mathrm{~kg}$ (4000 lbs) in water. The power amplifier, controlling electronics and computer are in the other half of the winch van, Figure 3. The source is connected to the Ling power amplifier via $1300 \mathrm{~m}$ of 0.680 -inch coaxial armored wire. The winch is used to deploy and recover the source package. The winch uses a $30 \mathrm{HP}, 240 \mathrm{~V} \mathrm{AC}, 100 \mathrm{~A}, 3$ phase input. For the test cruise on the R/V New Horizon, a $45 \mathrm{kVA}$ transformer was used to step down ships power voltage. The "control" portion of the van uses the same input. The same circuit breaker panel controls all the power for the winch, the low pressure compressor for the air tuggers, the high pressure compressor for filling the gas compensation bottles, the Ling power amplifier, and the $120 \mathrm{~V} \mathrm{AC} \mathrm{requirements} \mathrm{which} \mathrm{are} \mathrm{fed} \mathrm{through}$ a separate 3 KVA step down transformer.

\subsection{Glass Sphere Source Development and Implosion Modeling}

An implosive acoustic source is desirable because it offers the potential for SOFAR (Sound Fixing and Ranging) depth hydroacoustic calibration sources with the acoustic energy release of small explosions (nominally 1-5 lbs equivalent TNT) but without any of the hazards of explosives. This opens possibilities to obtain calibration shots on "ships of opportunity" with no hazards to ship crew or special skill and transport regulatory requirements. If the implosion system can be made simple and low cost, systems can used during cruises without the presence of principal investigators. Several versions of a controlled implosion system developed during this project are discussed below.

An imploding source exploits the pressure difference between an enclosed volume of gas at nominal atmospheric pressure and the external water pressure at the implosion depth. A sudden catastrophic failure of the containing vessel leaves the relatively low-pressure gas bubble exposed to relatively highpressure water and a rapid implosion ensues. The implosion momentum collapses the bubble radius to less than that required for an equilibrium pressure balance. At the instant of minimum bubble radius, the bubble begins expanding and radiates a positive (compressive) acoustic pressure spike. This oscillation can continue for a few cycles, each with successively reduced pressure spikes as energy is dissipated and the bubble approaches a static equilibrium pressure. In the case of underwater explosions, the initial shock wave is caused by ignition of the explosive and creation of an expanding gas globe filled with explosion gas products. There is no such analogue in an implosion. Another important difference is the relatively cold, low-pressure gas inside the sphere compared to the hot, high-pressure gas products in the explosion bubble. The bubble details of the two cases cannot be directly compared.

If a glass sphere is of sufficient volume to produce the desired source signal level and has sufficient wall thickness to survive the water pressures in the operational depth range, then sphere failure must be initiated by some controlled method at a predetermined depth. The method developed was designed to be rugged enough to be reusable, heavy enough to sink the whole assembly loaded with the sphere, and not dependent on stored energy at the surface (i.e. no electricity or compressed air). The device consists of two orthogonal cutout plates that hold the sphere and a cylinder-piston-ram assembly that punches a hole in the sphere. The system firmly holds the sphere in place and in contact with a 4-inch diameter piston (shown in Figure 14). A 1/4-inch diameter ram is connected to the center of the piston and passes through a small O-ring sealed hole in the cap confining the piston and abutting the glass sphere. The ram initiates failure by punching a hole through the glass sphere. The end-cap on the cylinder confining the piston and opposing the ram end-cap tapers to a one-inch diameter opening with a rupture disk seated to it. The 
rupture disk is calibrated to fail within $5 \%$ of the desired failure pressure. Failure of the rupture disk results in an inrush of high-pressure water into the air-filled piston chamber, driving the piston - and attached ram - towards the glass sphere.

Implosion tests shown below demonstrate that a single 22 liter sphere imploded at a nominal SOFAR channel depth (700 meters) results in a fairly high frequency acoustic pulse, with the bulk of the acoustic energy out of the monitoring band $(2-100 \mathrm{~Hz})$. Two methods that will tend to enhance the lower frequencies are to implode at a shallower depth or to implode a larger sphere volume. Imploding at a shallower depth has the drawbacks of producing a less energetic acoustic pulse due to the lower implosion pressures at shallower depths and less efficient coupling of the energy into the SOFAR channel, with the implosion presumably above the channel.

Increasing the implosion volume by increasing the diameter of the implosion sphere is impractical from a cost and operational standpoint. The 22-liter spheres we used are about the largest we have found commercially. To produce a significantly larger sphere would require special development and substantially thicker walls. Such a sphere would be costly, heavy, and large. We chose instead to cluster a number of the spheres together and thereby increase the overall volume of the implosion. A photograph of the original 1-sphere system and the prototype 5-sphere device is shown in Figure 15. The device consists of orthogonal steel plates that serve to hold the spheres in place, the same smashing cylinder as used in the single sphere system, and the five spheres. The idea is simple, smash one sphere and the rest will shatter in sympathy once the shock wave from the first implosion develops.

Figure 14. Conceptual view of the piston assembly. The rupture disk at the top keeps the cylinder volume above the piston at nominal atmospheric pressure (left). When the disk fails (right), high-pressure seawater rushes into the cylinder, driving the piston and ram downward.

In tests conducted with the 1-sphere system, the smashing system activated reliably in every case, resulting in catastrophic failure of the glass sphere and an implosion generated shock wave. The variation in failure depth (or failure pressure) observed in the tests was somewhat better than the

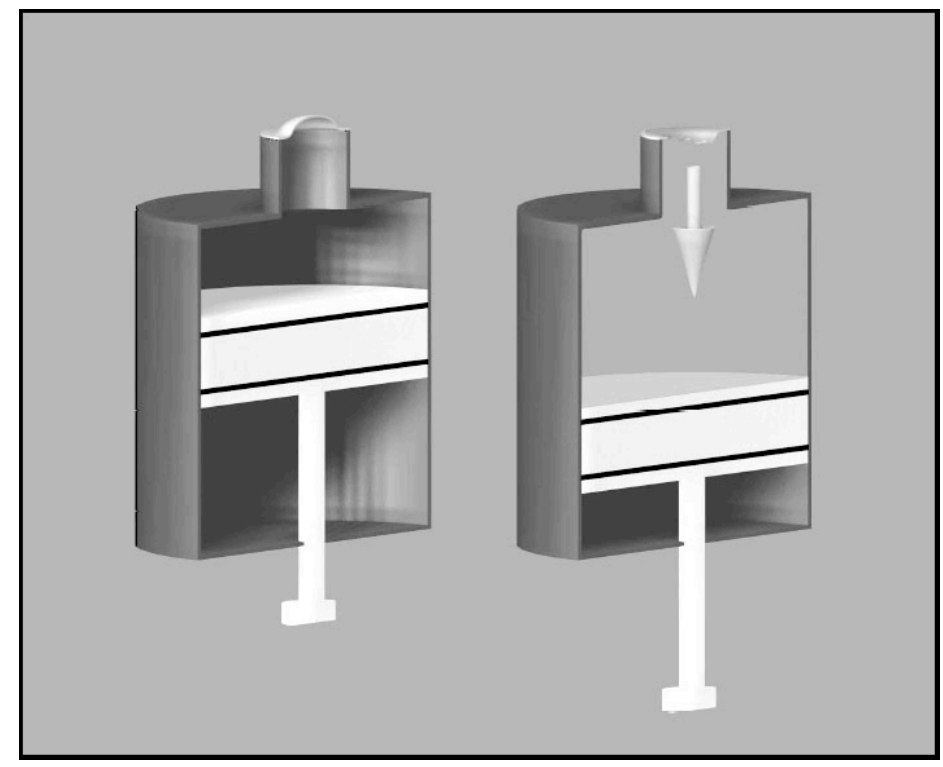
manufacturer's rupture disk failure specification of $+-5 \%$ of nominal. Our tests were closer to $+-3 \%$ of nominal. The smashing system on the 5-sphere system also performed reliably in every test. One 5-sphere test imploded prematurely due to a flaw in one of the spheres. This test yielded some important information on the sympathetic failure mechanism of the spheres as discussed below. The mechanical design of the 5-sphere system proved vulnerable to physical damage after repeated uses and also showed poor waveform repeatability. The poor repeatability is because the collective implosion is not radially symmetric and hence the resulting bearing dependent radiation pattern varies from shot to shot. The problems with the clustered 5 -sphere system should be solved with a linear 5-sphere system. An artist's conception of such a system is shown in Figure 16. The linear system should better survive repeated use and should provide a repeatable source waveform since the radiation pattern will not be bearing dependent. 


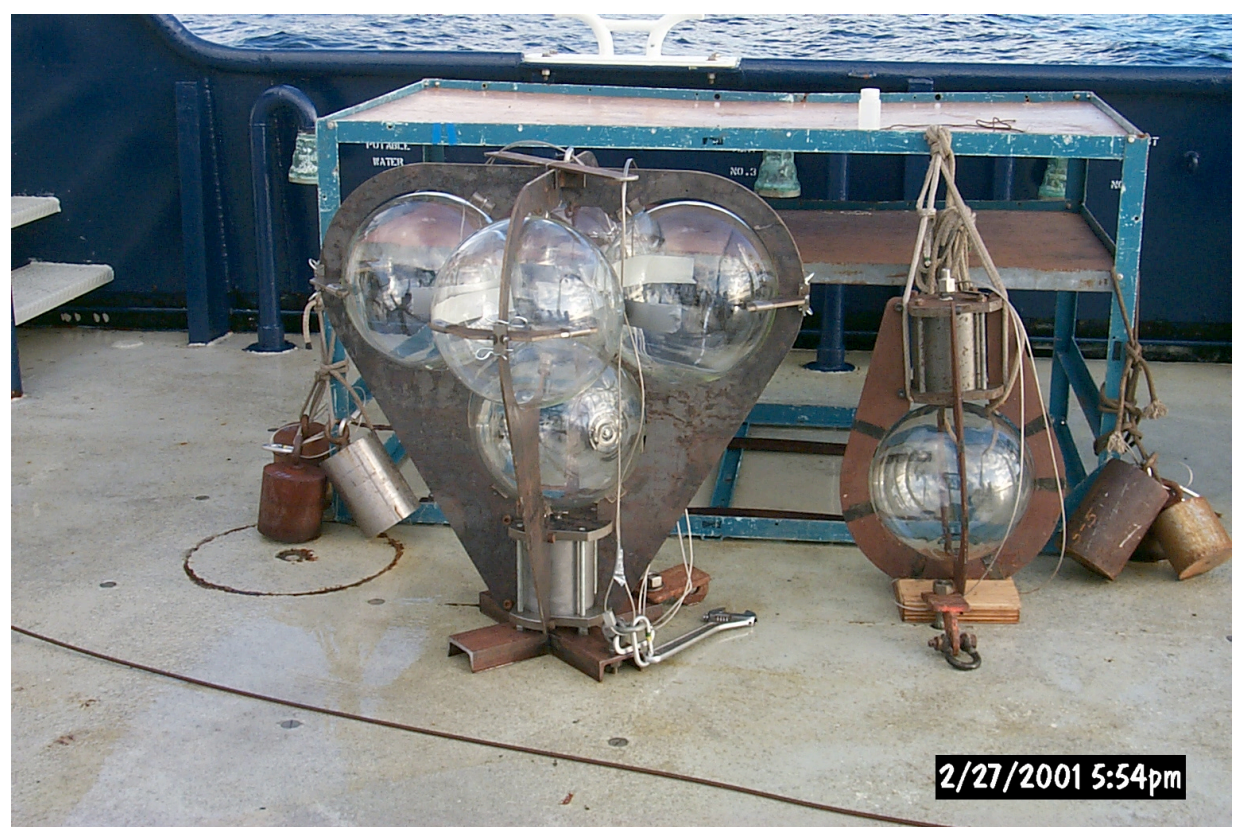

Figure 15. The two sphere smashing systems tested are shown. The original 1-sphere design is see on the right with the smashing cylinder at the top of the assembly. The 5sphere system is on the left with the smashing cylinder at the bottom of the assembly.

The single-sphere implosion source signal was recorded four times under similar conditions, though in widely varying locations. The implosions were conducted at nominally 680 meters depth and recorded with a hydrophone hung off the side of the ship, nominally 30 meters deep. The recordings are all overplotted in Figure 17. The repeatability of the source is apparent. This is an important result for calibration purposes because it allows for accurate transmission loss and other amplitude-dependent measurements. The characteristic features of the waveform show an acoustic signal generated by the inrush of seawater into the sphere volume after the failure of the containing glass. The acoustic signal is rarefactional (see Fig. 17, signal starting at $0.005 \mathrm{sec}$ and ending at $0.006 \mathrm{sec}$.) and hence negative referenced to ambient. This is followed by the primary peak associated with the major source of acoustic energy in the implosion. It develops at the instant of water convergence at the sphere center. A consistent trailing shoulder to the main peak and a low amplitude, high frequency signal just after the peak (see Fig. 17, signal centered at $0.0075 \mathrm{sec}$.) can also be observed. As will be seen in the modeling results, these features are probably due to the presence of the glass sphere during the implosion. Finally, a bubble pulse (signal observed between 0.0085 and 0.009 sec. in Figure 17) is observed at variable time delays after the main shock. The modeling results below indicate this timing variation is probably due to variation in the internal air pressure of the spheres.

Figure 16. Artists conception of a linear sphere implosion system design. As in past systems, the smashing system demonstrated to be reliable in 2001 and 2003 is used on the bottom sphere to induce sympathetic implosions in the other spheres. With such a system, any number of spheres can be utilized.

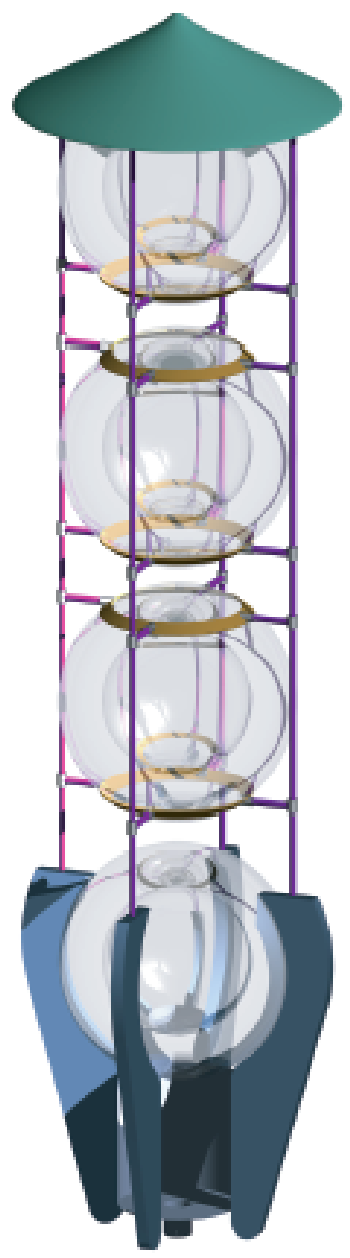




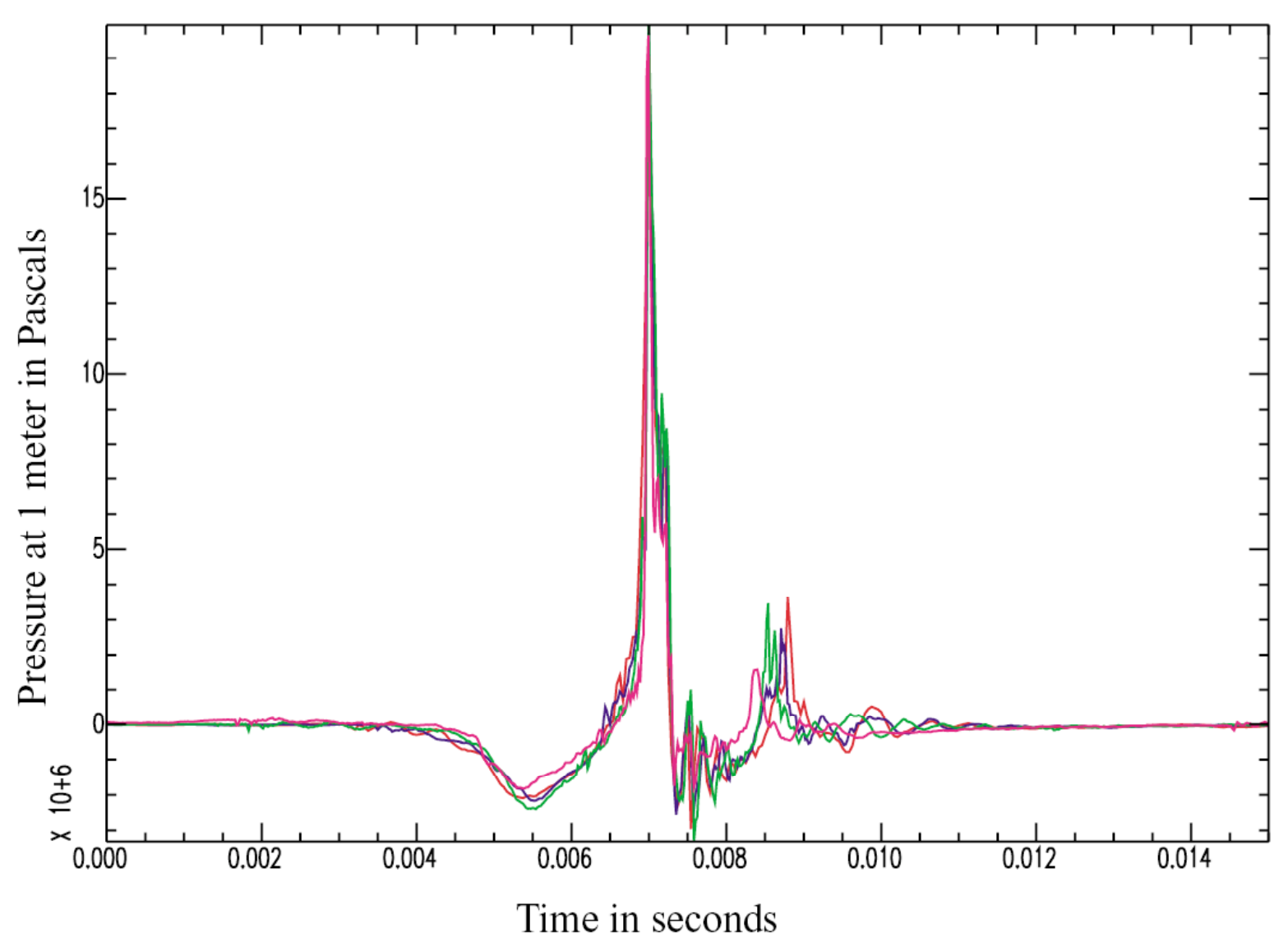

Figure 17. Waveforms created by several single sphere implosions repeated under similar conditions (680 meters depth and projected to 1 meter from the source). Note the good repeatability, especially for the implosion $(0.005-0.006 \mathrm{sec})$ and main shock.

The 5-sphere system had been tested once off the Pacific coast in 2001 at 137 meters depth (see Figure 18, left panel). During this test, one of the spheres failed and the resulting shock wave caused the other spheres to fail. This is evident in the recorded waveform. The beginning of the record has the characteristic signature of a single sphere implosion - the sphere that failed unintentionally; e,g., compare the Figure 18 (left panel) pulse between 0.045 and 0.055 sec. with the Fig 17 pulse between 0.0045 and $0.0075 \mathrm{sec}$. The time between the first sphere shock wave and the larger grouping of impulses (Figure 18 (left panel) pulse between 0.055 and $0.065 \mathrm{sec}$ ) that follow is controlled not by the acoustic propagation time between spheres but by the collapse time. The implosions at 680 meters (Figure 18, right panel) show a markedly different signature that can only be interpreted as a nearly simultaneous implosion of all 5 spheres due to the smashing cylinder. Apparently, the cracking propagates from sphere to sphere (which are touching) and hence the implosion timing of individual spheres is controlled by the acoustic propagation time. It is also evident that the 5-sphere system (Fig. 18) is not as repeatable as the 1-sphere source (Fig. 17) though the waveforms are similar. This is consistent with expectations if the spheres are failing nearly simultaneously. Such a failure does not have spherical symmetry and will consequently have a radiation pattern that is radially asymmetric. 


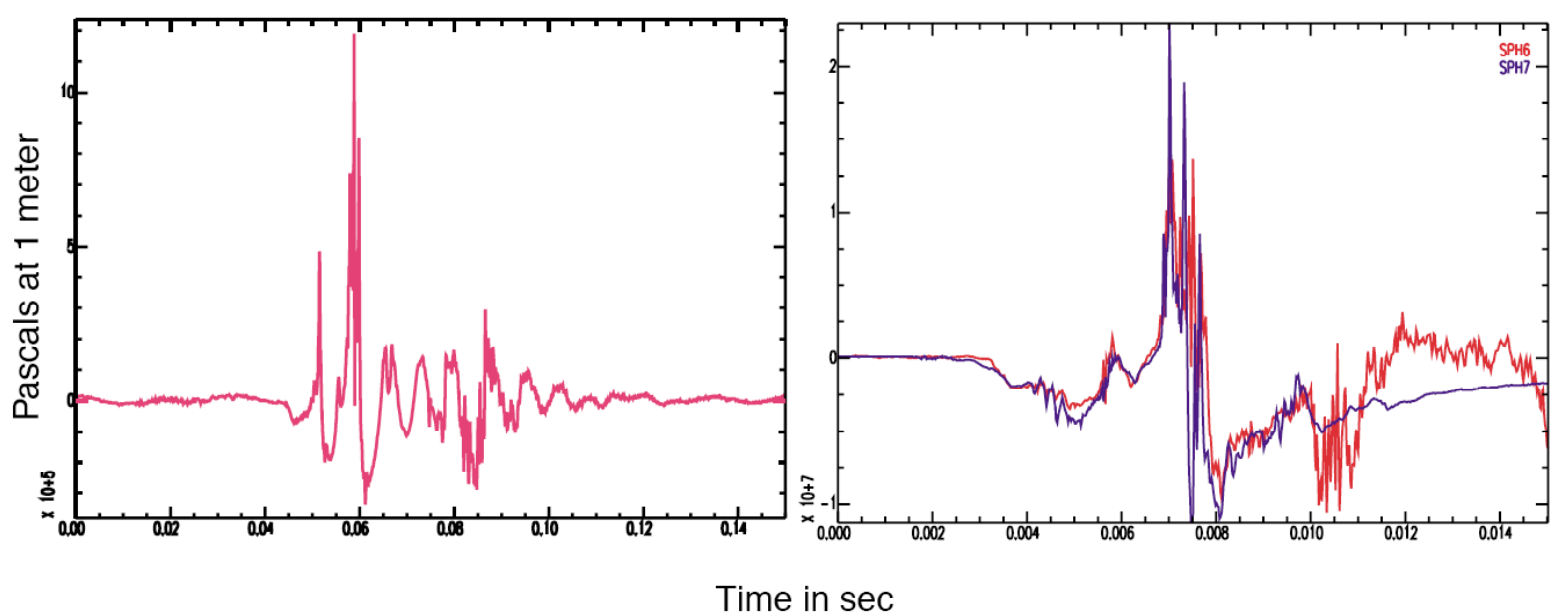

Figure 18. The 5-sphere implosion source waveforms are shown at 137 meters (left) and for two tests at 680 meters. Both plots are source overpressure at 1 meter in Pascals. The horizontal axis is time in seconds. Note that the 137 meter test was initiated by unintended failure of a glass sphere. The 680 meter tests were initiated as designed by the smashing system.

The sphere source signal was modeled using the hydrodynamic code CALE ( $\underline{\mathrm{C}}$-code, $\underline{\text { Arbitrary }}$ Lagrangian, Eulerian) to predict overpressures at 1 meter from the source. Several models were run varying only the internal pressure of the sphere. Peak pressures increased as the sphere internal air pressure decreased while the bubble pulse period and amplitude decreased with decreasing internal pressure. When the internal pressure was a sixth of standard atmospheric pressure, the peak pressure matches field tests. We infer that internal air pressures resulting from the high temperature manufacture of the glass spheres were very close to one-sixth standard atmospheric pressure. The large change in bubble pulse frequency with internal sphere pressure best explains the observed variation in the bubble pulse frequency of the field tests. Although implosion depth can also affect bubble pulse frequency, the implosion depths did not vary more than $3 \%$. This depth variation is too small to account for the observed differences. Conversely, since the spheres are hand blown, it is likely that the air temperature and hence pressure at the time of sealing the sphere closed could vary significantly. Figure 19 shows the modeled signal waveform of the source.

The basic implosion model was modified to include a shell of fluid with the density and mass of the glass sphere. Including a glass-like fluid in the model gave rise to a trailing shock peak shoulder, high frequency "hash" and it resulted in a sharper or pointed bubble pulse. The modeled results are shown in the top plot of Figure 20 and compared to the field tests (bottom plot). The field tests shown in the bottom plot have those same features and consequently we can conclude that the density contrast of the glass plays some role in the waveform complexities observed in the field tests. The model differs notably from test results in the shock wave pulse width and the bubble pulse period. Both differences may be the result of the crushing of the solid glass that must be occurring but that is not captured in the simplified model. 


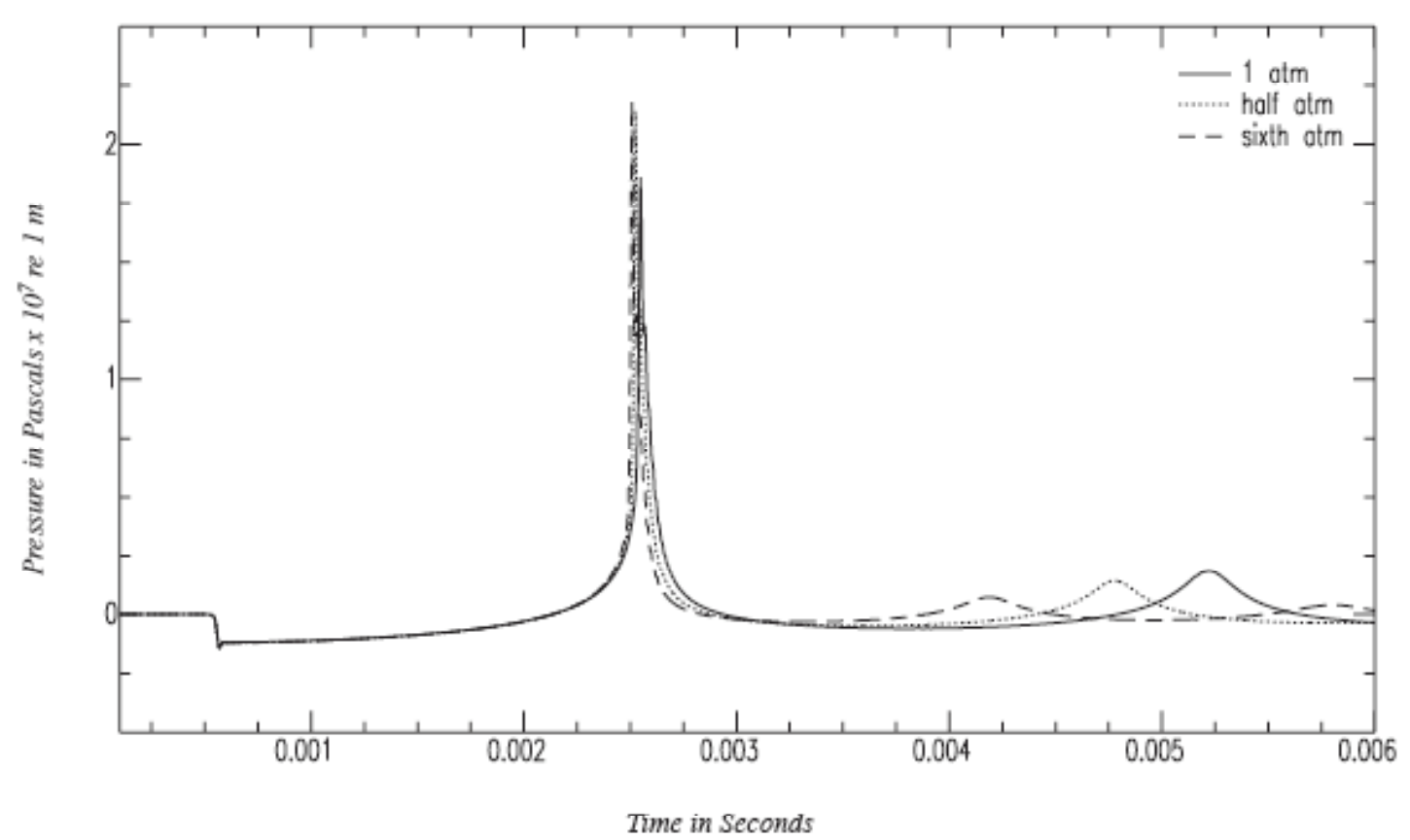

Figure 19. Three idealized implosion waveforms modeled with CALE. The implosion depth and sphere volume match field test conditions (22 liter volume at 680 meters depth) but the glass shell is not accounted for. Note the waveform is calculated for different initial internal sphere pressures, all other parameters constant.

The most sophisticated CALE modeling of the single sphere implosion is shown in Figure 21. The modeling includes the glass shell density contrast and accounts for the finite crack propagation time around the sphere. This is modeled by allowing the sphere to begin collapsing at the left side equator and delaying the release of other sphere annuli sections by the acoustic propagation time in glass, finally reaching the right side equator. The left plot shows the conditions at minimum collapse volume. The outer scalloped dark line marks the water-glass boundary. The scalloping is a numerical artifact of the finite number of annular sections used in the model. The inner dark line marks the glass-air boundary. The varying delay in wall collapse allows the initial collapse point on the left to push the collapse to the right to produce a complex non-symmetric implosion with peak pressures occurring in the glass to the left of the compressed air but to the right of the initial center point of the sphere. The right plot shows the resulting shock wave radiating outwards at nearly 1 meter distance (note the E1 for x10 and E2 for x100 in the distance scales in the two plots). Despite the complexity of the implosion, the shock wave is spherically symmetric wave front but the pressures are much higher opposite the initial collapse equator. This result has implications for designing directional implosion systems but remains untested in the field. 


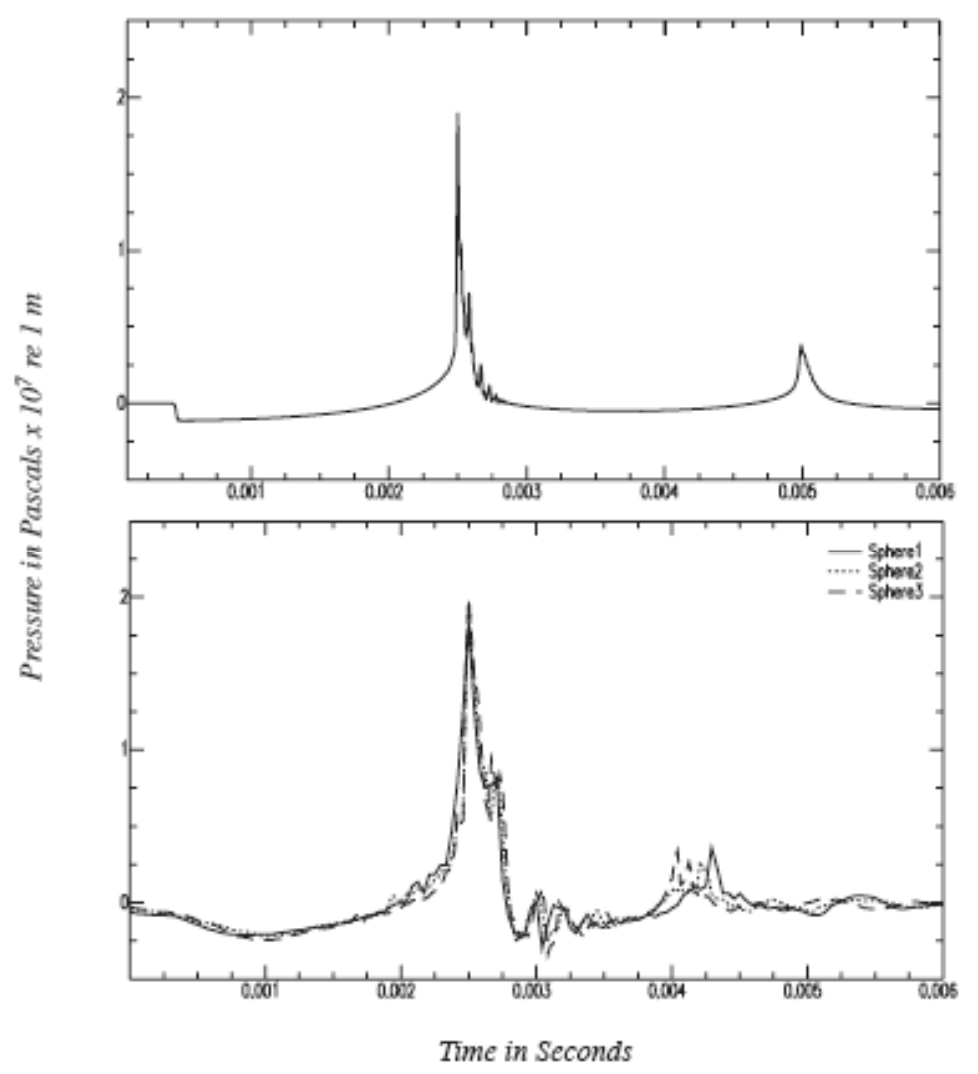

Figure 20. The modeled single sphere implosion source signal when the model accounts for the mass and density contrast of the glass shell (top plot) compared to three field tests at 680 meters depth (bottom plot).
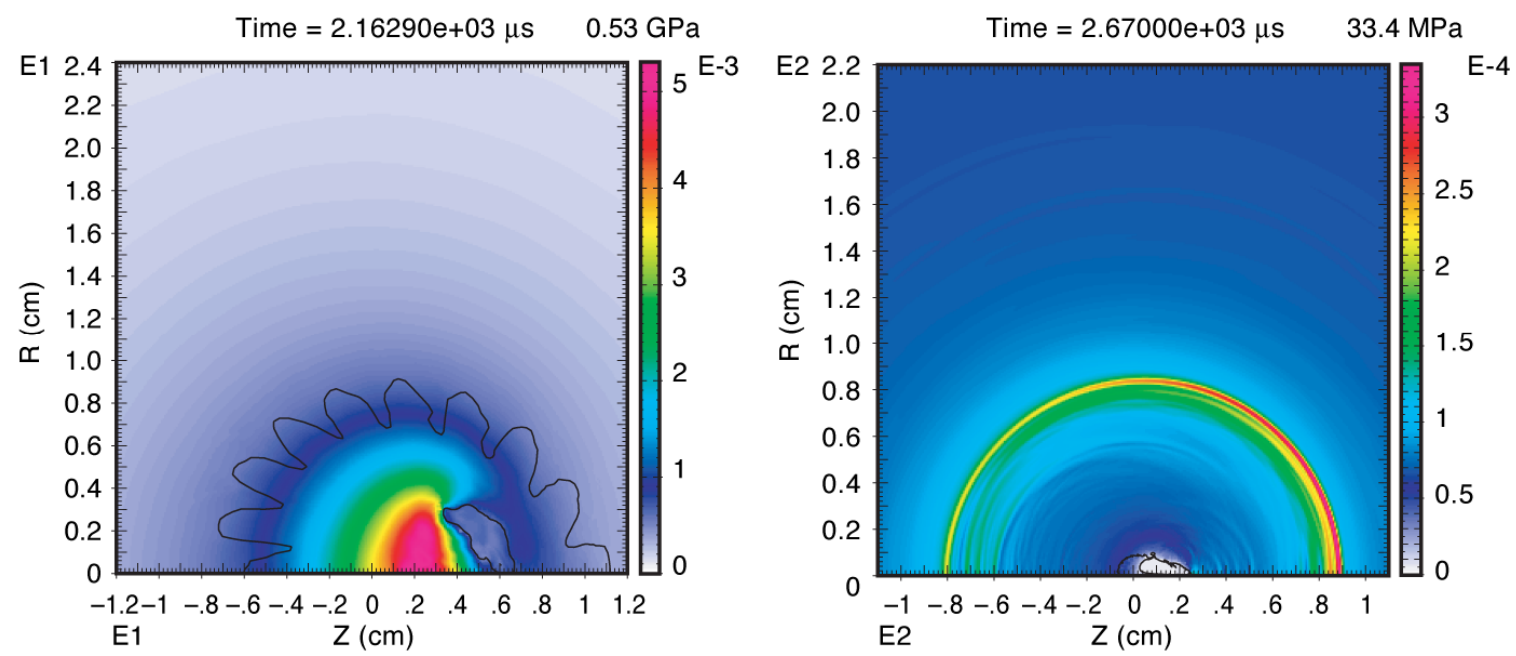

Figure 21) Pseudocolor plot of modeled pressures at two instants of time in the implosion collapse and shock wave evolution when the finite crack propagation time is accounted for. Cracking is initiated on the left and propagates to the right. The left plot is at the instant of complete air-pocket collapse. The right plot is after the shock wave has traveled nearly 1 meter from the implosion. 


\subsection{Transmission loss modeling}

A range dependent elastic parabolic equation (PE) algorithm was used by de Groot-Hedlin to obtain a first order estimate of acoustic loss for an $8 \mathrm{~Hz}$ signal along the source-receiver paths that correspond to the 2001 airgun shots. Several simplifications were made: seawater properties are assumed to be sufficiently range-independent that backscatter may be ignored; propagation is assumed to be accurately approximated as a 2-D problem; source-receiver path was geodesic; oceanic properties and depths vary along each path but elastic structure beneath the seafloor was constant.

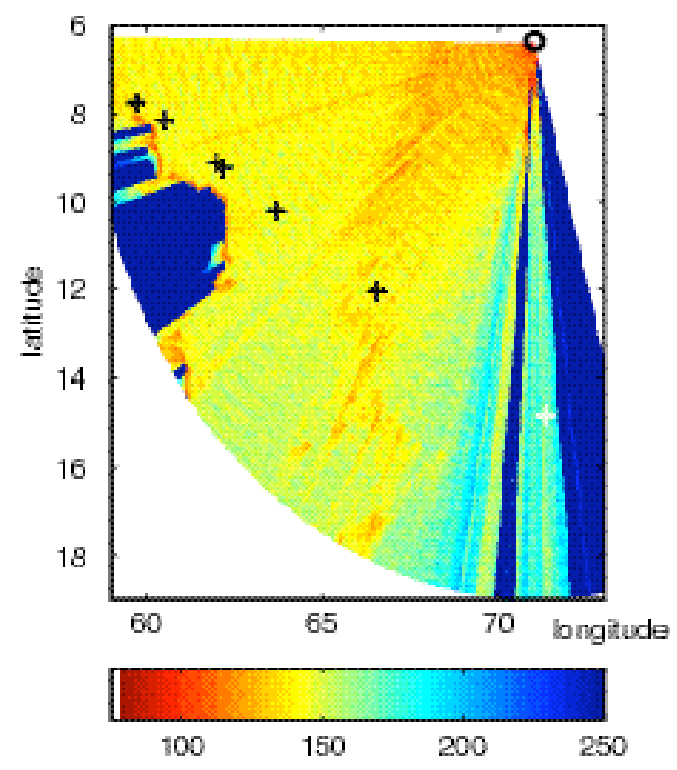

Figure 22. Map of predicted acoustic transmission loss from a $12 \mathrm{~m}$ deep airgun array source to Diego Garcia (H8N01). Red indicates a source region for which the losses along the source-receiver path are low; blue indicates a source region for which alongpath losses are high. Scale is $\mathrm{dB}$ re $\mu \mathrm{Pa} / \mathrm{Hz}$. crosses indicate location of airgun array shooting sites.

The estimated transmission loss at $\mathrm{H} 08 \mathrm{~N}$ was significant for sites air6-9 (Appendix A, Table 1), and at H08S the losses for sites air 1-3 are also quite high, due to effective topographic blockage. Relative loss levels calculated at $\mathrm{H} 08 \mathrm{~N}$ for sites air 1 and air 2 (Figure 22) are similar to what was observed in the $5-10 \mathrm{~Hz}$ range. The estimated loss at 8 $\mathrm{Hz}$ for air3-5 is several decibels greater for $\mathrm{H} 08 \mathrm{~N}$ than what was observed. The could be due to rough seafloor along the Central Indian RiH08e that is not accounted for in the bathymetry model employed in the calculation. Gaps in the ridge crest may allow sound to propagate without as much bottom interaction as is modeled, at $8 \mathrm{~Hz}$, by the more smoothly varying (therefore more continuous) ridge crest. At higher frequencies, the smoothness of the model would affect the results in the opposite direction. The detailed features may scatter energy near the source so that the actual transmission loss is greater. Although both had good SNR, transmission loss between the airgun source and the receivers was significantly lower for air 5 shots than for air2 shots (Fig. 23). Calculated transmission loss for air7 is similar to that for air 9 in the $20-90 \mathrm{~Hz}$ band when signal was more than $3 \mathrm{~dB}$ above background noise (Fig. 23).

Figure 23. Observed transmission loss for each source-receiver pair. The median value of loss for all shots at each site is plotted. Curvse shows only frequencies where signal exceeded background noise levels by $3 \mathrm{~dB}$. At HOSN, air4 loss is very similar to airl-air3 losses in the 5-8 Hz band. 


\section{CONCLUSIONS}

All the sources tested for this project except the MPL/SIO triggered cylinder imploder generate signals that were detected at long range. The single-sphere glass implosions were detected out to ranges on the order of $1000 \mathrm{~km}$. The five-sphere implosions, the SUS charges, and many of the airgun array shots were recorded at ranges of a few thousand $\mathrm{km}$. Therefore, we have documented several viable sources for future efforts to achieve basin-wide calibration of the IMS hydroacoustic capabilities. The plan required for effective use would differ for the various sources. For several of our small acoustic signals, the source location determined from IMS data analysis agreed with the actual location within acceptable limits. However, uncertainties in arrival time associated with long signals whose complexity arose from topographic scattering along the source-receiver path, led to unacceptably large errors in some determined source locations. The data obtained for this project do not allow us to assess how this type of problem might scale as a function of source magnitude, which would typically be much larger for an actual nuclear test.

\section{PUBLICATIONS}

Blackman, D.K., J.A. Mercer, R. Andrew, C. de Groot-Hedlin, P.E. Harben, Indian Ocean calibration tests: Cape Town - Cocos Keeling (2003) Proc. $25^{\text {th }}$ Seismic Res. Rev., paper 5-01.

Blackman, D.K., de Groot-Hedlin, C., Harben, P., Sauter, A., Orcutt, J.A. (2004). Testing low/very low frequency acoustic sources for basin-wide propagation in the Indian Ocean. J. Acoust. Soc. Amer. 116, DOI: $10.1121 / 1.1786711$.

Hagelberg, J., (2003), CALE Implementation Guide, Lawrence Livermore National Laboratory, Livermore, California, UCRL-ID-155540, September 2003.

Harben P.E., Boro, C., Dorman, L., Pulli, J. (2000) Use of imploding spheres: an alternative to explosives as acoustic sources at mid-latitude SOFAR channel depths, University of California Publ. UH04L-ID139032.

Harben, P.E. and Boro, C. (2001) Implosion source development and Diego Garcia reflections, Proc. $23^{\text {rd }}$ Seismic Res. Rev., 23-31.

Harben, P., C. de Groot-Hedlin, and D. Blackman (2002) Acoustic Sources for Blockage Calibration of Ocean Basins: Results from the October 2001 Indian Ocean Cruise, Proc. $24^{h}$ Seismic Res. Rev., paper 4-03.

Harben, P.E., E. Matzel, D.K. Blackman, D. Clarke (2004) Hydroacoustic blockage calibration for disH04imination: results from 2003 Indian Ocean cruise, and imploding sphere calibration source development, Proc. 27th Seismic Res. Rev., paper 5-01.

Sauter, A.W., Dorman, L.M. (2003) Designing a Deep-Towed/Seafloor Repetitive Sound Source, Eos Trans. AGU 84(46), Abstract S52D-0163. 


\section{APPENDIX A}

Table I. Airgun array shot lines during 2001 (start/end).

(listing of individual shots available at mahi.ucsd.edu/dkb/ew0112.html)

\begin{tabular}{|c|c|c|c|c|c|c|c|c|c|c|}
\hline jd & $h r: m n$ & $1 a$ & $t(S)$ & Ion & $(E)$ & seafloor & int & erval & site $s$ & shot\# \\
\hline 280 & $19: 14$ & $7^{\circ} 4$ & $46.1^{\prime}$ & $59^{\circ} 4$ & $16^{\prime}$ & $2110 \mathrm{~m}$ & 97 & sec air 1 & $1-9$ & \\
\hline 280 & $19: 27$ & 7 & 46.2 & 59 & 42.5 & 2145 & & & & \\
\hline 280 & $19: 33$ & 7 & 46.3 & 59 & 42.9 & 2205 & & 173 & & $11-14$ \\
\hline 280 & $19: 42$ & 7 & 46.5 & 59 & 43.4 & 2270 & & & & \\
\hline 281 & $02: 38$ & 8 & 8.5 & 603 & 0.7 & 2575 & 127 & $\operatorname{air} 2$ & $22-35$ & \\
\hline 281 & $03: 03$ & 8 & 9.5 & 603 & 2.1 & 2655 & & & & \\
\hline 281 & $16: 48$ & 9 & 13.7 & 62 & 09.8 & 2645 & 173 & $\operatorname{air} 3$ & $36-46$ & \\
\hline 281 & $17: 17$ & 9 & 14.7 & 62 & 11.5 & 2720 & & & & \\
\hline 282 & $05: 22$ & 10 & 12.2 & 63 & 40.9 & 3540 & 57 & $\operatorname{air} 4$ & $49-59$ & \\
\hline 282 & $05: 31$ & 10 & 12.6 & 63 & 41.6 & 3530 & & & & \\
\hline 282 & $05: 38$ & 10 & 12.7 & 63 & 41.8 & 3520 & 173 & & $61-68$ & \\
\hline 282 & $05: 58$ & 10 & 13.4 & 63 & 42.8 & 3660 & & & & \\
\hline 283 & $04: 33$ & 12 & 01.8 & 66 & 30.6 & 2965 & 127 & $\operatorname{air} 5$ & $69-83$ & \\
\hline 283 & $05: 03$ & 12 & 02.6 & 66 & 32.2 & 3330 & & & & \\
\hline 284 & $15: 34$ & 14 & 48.3 & 71 & 19.5 & 4850 & 173 & air6 & $86-96$ & \\
\hline 284 & $16: 03$ & 14 & 49.5 & 71 & 20.8 & 4875 & & & & \\
\hline 289 & $02: 11$ & 22 & 55.5 & 87 & 02.8 & 3370 & 127 & $\operatorname{air} 7$ & $99-114$ & \\
\hline 289 & $02: 43$ & 22 & 54.6 & 87 & 00.7 & 3455 & & & & \\
\hline 289 & $02: 45$ & 22 & 54.6 & 87 & 00.7 & 3445 & 57 & & $115-12$ & \\
\hline 289 & $02: 58$ & 22 & 54.3 & 87 & 00.0 & 3550 & & & & \\
\hline 289 & $12: 28$ & 23 & 25.0 & 88 & 11.3 & 2985 & 173 & $\operatorname{air} 8$ & $129-13$ & \\
\hline 289 & $12: 57$ & 23 & 25.6 & 88 & 13.3 & 3240 & & & & \\
\hline 289 & $12: 59$ & 23 & 25.6 & 88 & 13.5 & 3235 & 57 & & $140-14$ & \\
\hline 289 & $13: 04$ & 23 & 25.7 & 88 & 13.9 & 3105 & & & & \\
\hline 292 & $02: 10$ & 27 & 33.2 & 98 & 51.6 & 2710 & 57 & $\operatorname{air} 9$ & $147-17$ & \\
\hline 292 & $02: 32$ & 27 & 33.7 & 98 & 53.0 & 2800 & & & & \\
\hline 292 & $02: 35$ & 27 & 33.8 & 98 & 53.2 & 2810 & 127 & & $171-17$ & \\
\hline 292 & $02: 46$ & 27 & 34.0 & 98 & 53.9 & 2845 & & & & \\
\hline
\end{tabular}


Table 2. MPL/SIO Imploding Cylinder Shots

\begin{tabular}{|c|c|c|c|c|c|c|}
\hline year & jd & $h r: m n: s e c$ & stn & latitude(S) & longitude(E) & source (m) \\
\hline 20 & 282 & $07: 18: 09.13$ & imp2 & $10^{\circ} 15.0479^{\prime}$ & $63^{\circ} 45.0703^{\prime}$ & 1000 \\
\hline 2001 & 284 & $18: 00: 50.14$ & imp4 & $14 \quad 46.026$ & $71 \quad 17.117$ & 1000 \\
\hline 2001 & 286 & $04: 30: 50.14$ & imp5 & $17 \quad 41.2828$ & 7626.2046 & 1200 \\
\hline 2001 & 292 & $04: 00: 30.1$ & imp6 & $27 \quad 27.0660$ & $98 \quad 33.9000$ & $1200-1315$ \\
\hline 2001 & 94 & $07: 27: 15.09$ & imp 7 & $30 \quad 21.4746$ & $108 \quad 20.2620$ & 1000 \\
\hline
\end{tabular}

Table 3. Imploding Glass Single-Sphere Shots

$\begin{array}{llllccc}\text { year jd } & \text { hr:mn:sec } & \text { stn } & \text { latitude(S) } & \text { longitude(E) } & \text { source (m) } \\ 2001 & 283 & 06: 25: 12.39 & \text { sph1 } & 12^{\circ} 03.8883^{\prime} & 66^{\circ} 34.5404 & 680 \\ 2001 & 284 & 14: 24: 54.5 & \text { sph2 } & 1446.0701 & 7117.0669 & 320 \\ 2001 & 284 & 18: 48: 00.73 & \text { sph3 } & 1446.0624 & 7117.2791 & 670 \\ 2001 & 286 & 05: 17: 07.82 & \text { sph4 } & 1741.4825 & 7626.2167 & 670 \\ 2003 & 140 & 13: 26: 23.33 & \text { A1 } & 3403.381 & 4030.159 & 710 \\ 2003 & 143 & 13: 47: 29.06 & \text { A3 } & 3149.640 & 5236.594 & 690 \\ 2003 & 152 & 08: 46: 44.89 & \text { A8 } & 1710.552 & 8340.514 & 725\end{array}$

Table 4. Imploding Glass Five-Sphere Shots

$\begin{array}{lllllrc}\text { year jd } & \text { hr:mn:sec } & \text { stn } & \text { latitude(S) } & \text { longitude(E) } & \text { source(m) } \\ 2001 & 312 & 15: 10: 00 & \text { sph6 } & 17^{\circ} 40.827^{\prime} & 109^{\circ} 32.643^{\prime} & 690 \\ 2001 & 330 & 16: 09: 40 & \text { sph7 } & 2201.225 & 11043.585 & 680 \\ 2003 & 144 & 10: 23: 11.56 & \text { A4 } & 3052.227 & 5619.051 & 715 \\ 2003 & 146 & 06: 18: 34 & \text { A5 } & 2844.111 & 6324.094 & 726 \\ 2003 & 151 & 04: 20: 17.85 & \text { A7 } & 1826.050 & 8055.093 & 713 \\ 2003 & 160 & 01: 37: 39.90 & \text { A11 } & 1311.875 & 10441.665 & 731\end{array}$

\begin{tabular}{|c|c|c|c|c|c|c|}
\hline year & jd & $h r: m n: s e c$ & stn & latitude(S) & longitude(E) & source $(m)$ \\
\hline 2003 & 140 & $13: 55: 09.15$ & A1 & $34^{\circ} 03.382^{\prime}$ & $40^{\circ} 30.157^{\prime}$ & 915 \\
\hline 2003 & 140 & $14: 04: 59.23$ & A1 & $34 \quad 03.384$ & $40 \quad 30.156$ & 610 \\
\hline 2003 & 142 & $13: 35: 02$ & $\mathrm{~A} 2$ & $32 \quad 51.157$ & $47 \quad 44.150$ & 915 \\
\hline 2003 & 142 & $13: 39: 47.39$ & A2 & 3251.142 & $47 \quad 44.139$ & 610 \\
\hline 2003 & 144 & $10: 54: 57.77$ & A3 & $30 \quad 52.227$ & $56 \quad 19.046$ & 915 \\
\hline 2003 & 144 & $10: 59: 49.04$ & A4 & $30 \quad 52.223$ & $\begin{array}{ll}56 & 19.049\end{array}$ & 610 \\
\hline 2003 & 146 & $06: 48: 38$ & A5 & $28 \quad 44.104$ & $63 \quad 24.095$ & 915 \\
\hline 2003 & 146 & $06: 52: 38$ & A5 & $28 \quad 44.115$ & $63 \quad 24.097$ & 610 \\
\hline 2003 & 149 & $04: 20: 21.90$ & A6 & $22 \quad 05.089$ & $72 \quad 44.529$ & 915 \\
\hline 2003 & 149 & $04: 25: 51.21$ & A6 & 2205.089 & $72 \quad 44.529$ & 610 \\
\hline 2003 & 151 & $11: 52: 11.75$ & A7 & 1826.045 & $80 \quad 55.091$ & 915 \\
\hline 2003 & 151 & $11: 59: 15.81$ & A7 & 1826.045 & $80 \quad 55.091$ & 610 \\
\hline 2003 & 152 & $09: 13: 59.37$ & A8 & 1710.555 & 8340.506 & 610 \\
\hline 2003 & 152 & $09: 19: 59.23$ & A8 & 1710.555 & 8340.506 & 610 \\
\hline 2003 & 156 & $10: 48: 48.10$ & A9 & 1329.673 & 9141.316 & 915 \\
\hline 2003 & 158 & $03: 55: 21.68$ & A10 & $12 \quad 12.799$ & $96 \quad 47.799$ & 915 \\
\hline 2003 & 160 & $00: 37: 33.83$ & A11 & 1311.878 & $104 \quad 41.661$ & 915 \\
\hline
\end{tabular}




\section{APPENDIX B. Spectra, Back Azimuths And Travel-Times, 2003 Cruise}

The figures in this appendix have a common format. Spectral amplitude (units in instrument counts) is plotted against linear frequency scale $(0-100 \mathrm{~Hz})$. The red curves show the spectra of the signal recorded by the three hydrophones averaged, for each IMS station and a given source arrival. The blue curves show spectra of the average over the three sensors of noise, for each station, for a 6-s period, 20 seconds before the predicted arrival time for a given event. The predicted/observed back azimuths are shown by blue/red arrows. The predicted azimuth is calculated assuming a great circle path. Travel times are listed; predicted times assume a sound speed of $1.485 \mathrm{~km} / \mathrm{s}$.

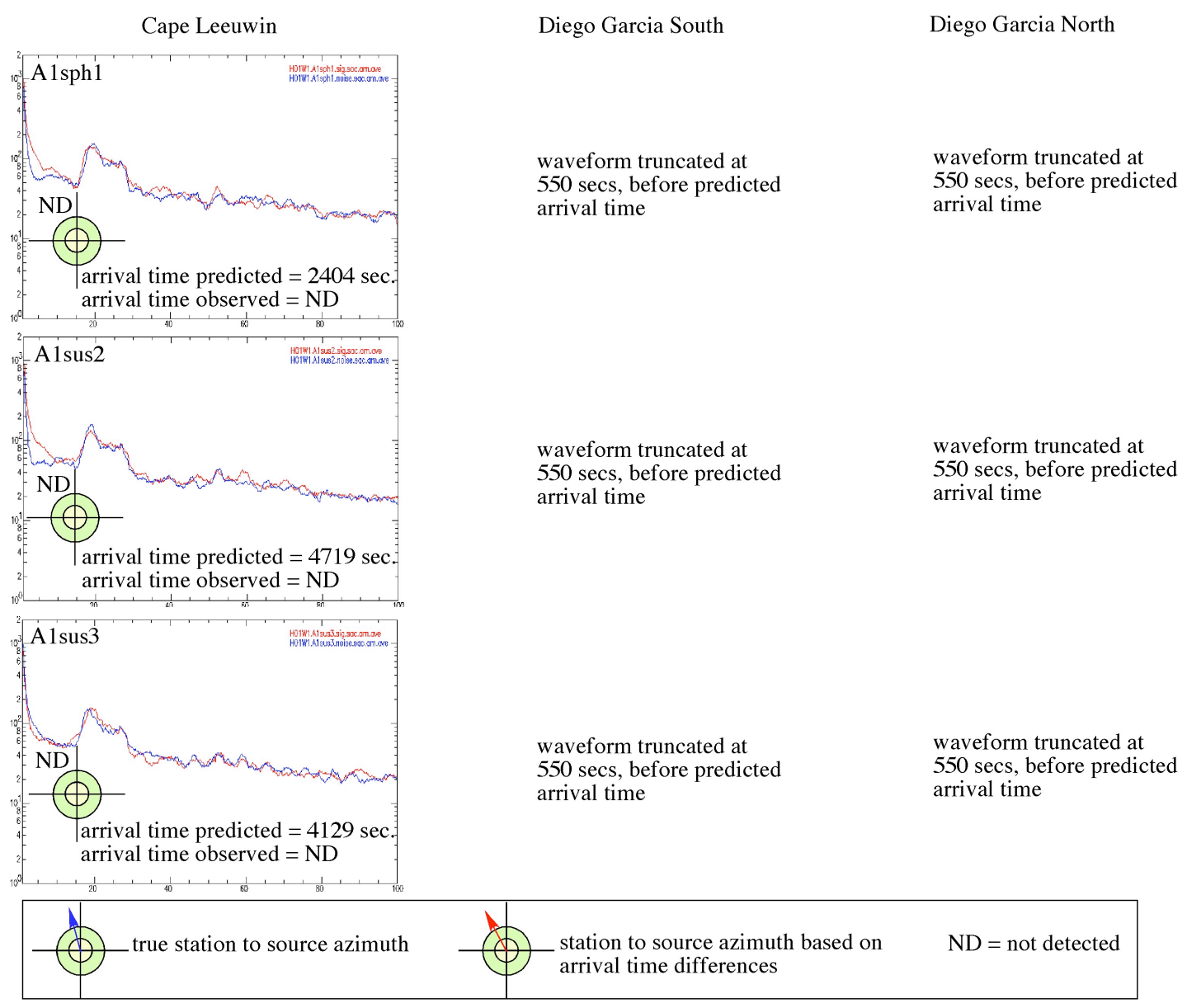

Figure B1. Spectra for sources at site Al as recorded at the H01 (left column), HOSS (middle column) and H08N (right column) stations. The sources consisted of one imploding sphere (710 m depth, top row), a $1.8 \mathrm{lb}$ SUS charge at $610 \mathrm{~m}$ depth (middle row) and a $1.8 \mathrm{lb}$ SUS charge at $915 \mathrm{~m}$ depth (bottom row). 
Cape Leeuwin
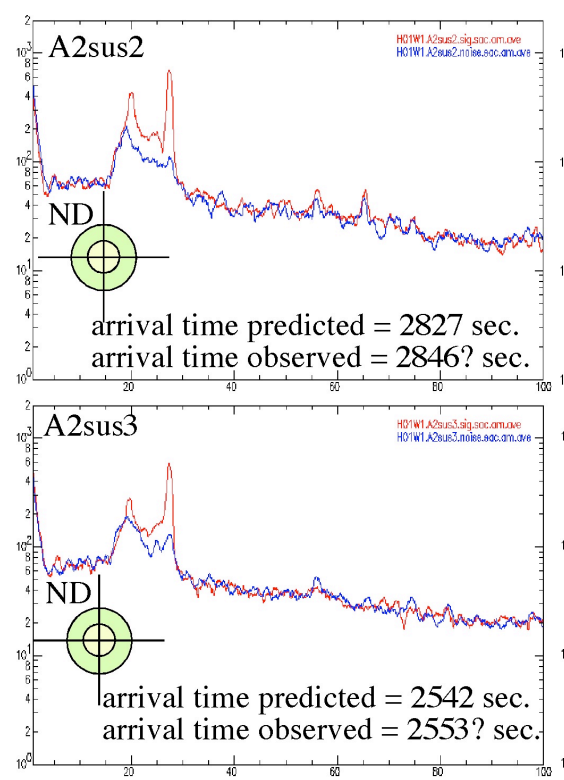

Diego Garcia South
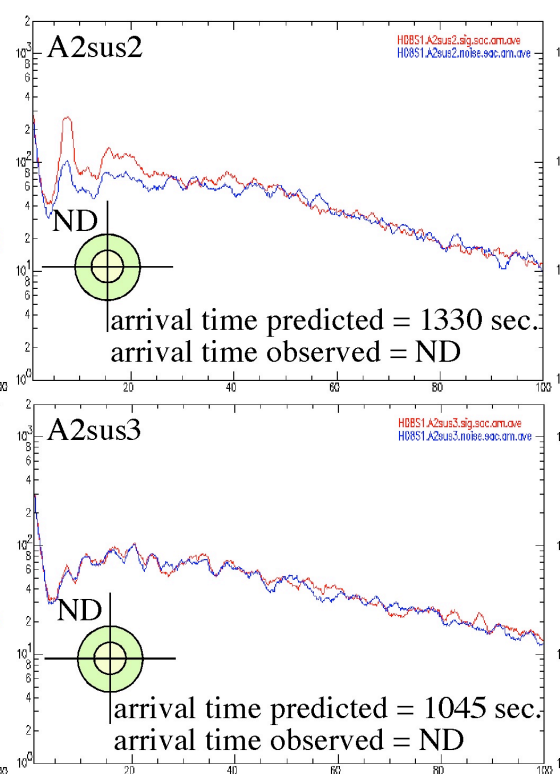

Diego Garcia North
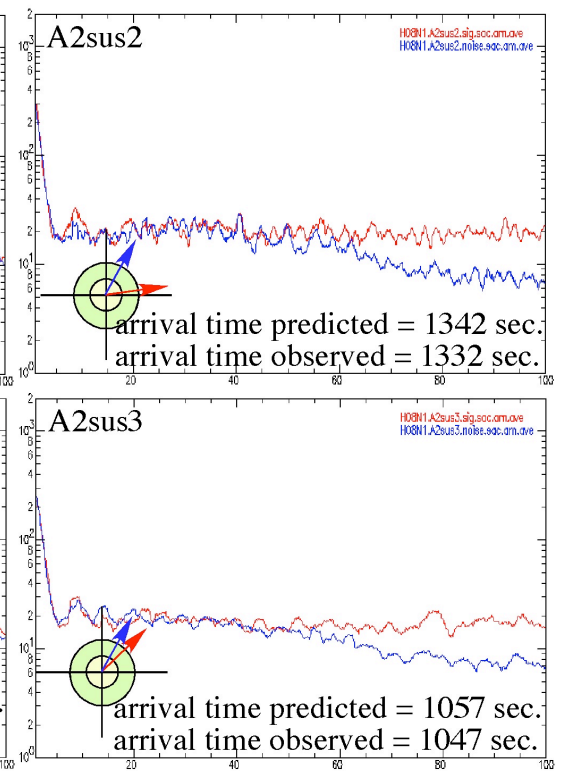

Figure B2. Spectra for sources at site A2 at H01 (left column), H08S (middle column), and H08N (right column). The sources consisted of a $1.8 \mathrm{lb}$ SUS charge at $610 \mathrm{~m}$ depth (top row) and a $1.8 \mathrm{lb}$ SUS charge at 915 m depth (bottom row).

Cape Leeuwin

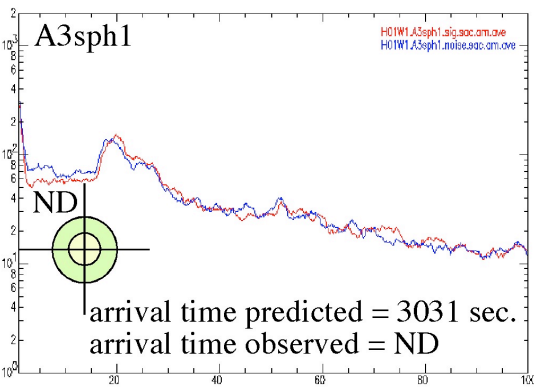

Diego Garcia South

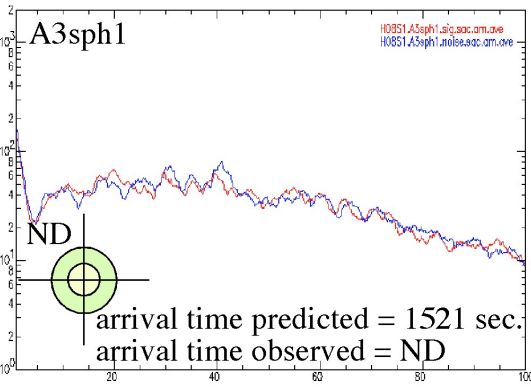

Diego Garcia North

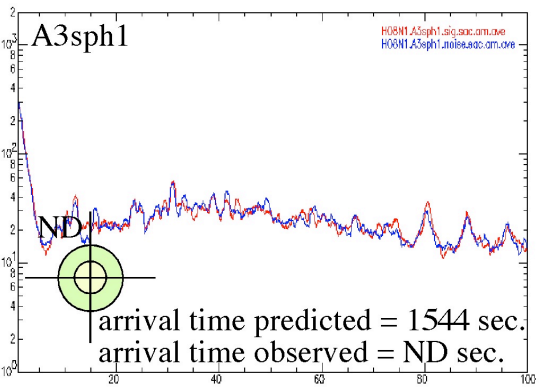

Figure B3. Spectra for sources at site A3. The source was a single-sphere glass implosion at $690 \mathrm{~m}$ depth. 
Cape Leeuwin

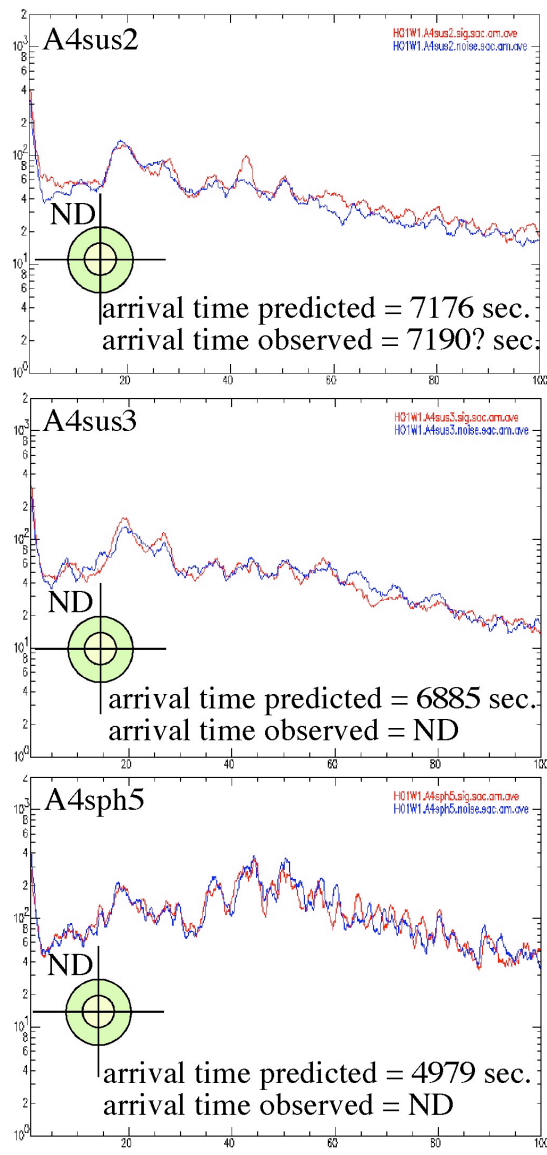

Diego Garcia South
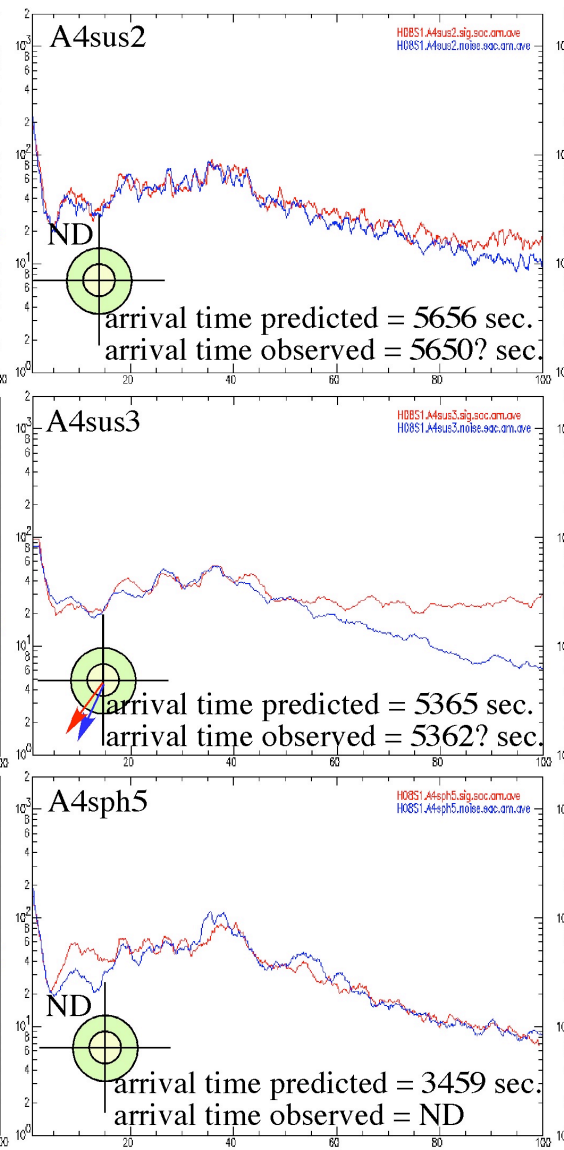

Diego Garcia North
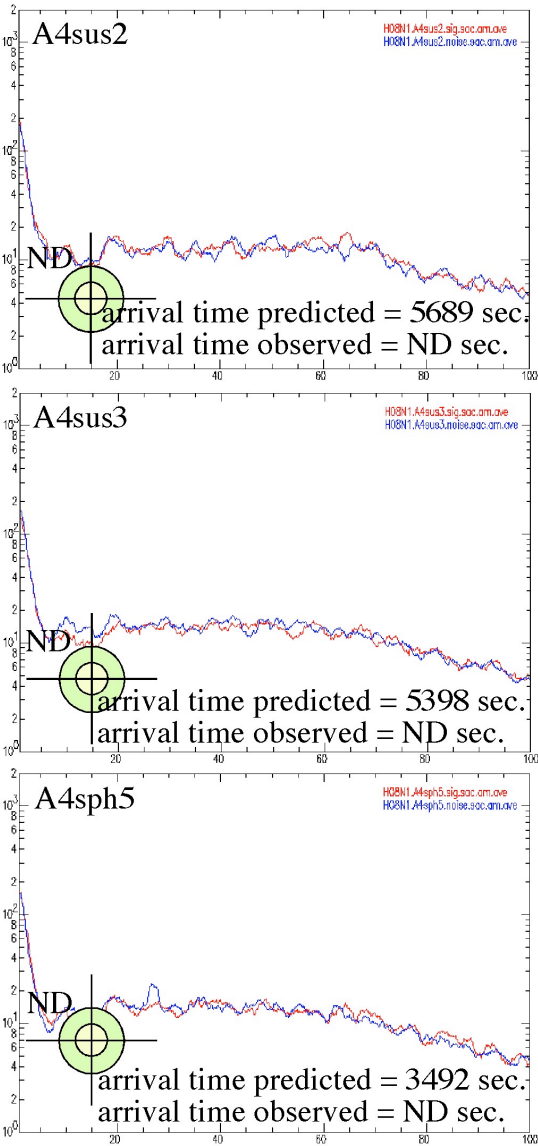

Figure B4. Spectra for sources at site A4. The sources consisted of a $1.8 \mathrm{lb}$ SUS charge at $610 \mathrm{~m}$ depth (top row) and a $1.8 \mathrm{lb}$ SUS charge at $915 \mathrm{~m}$ depth (middle row), and a five-sphere glass implosion at 715 $m$ depth (bottom row). 
Cape Leeuwin

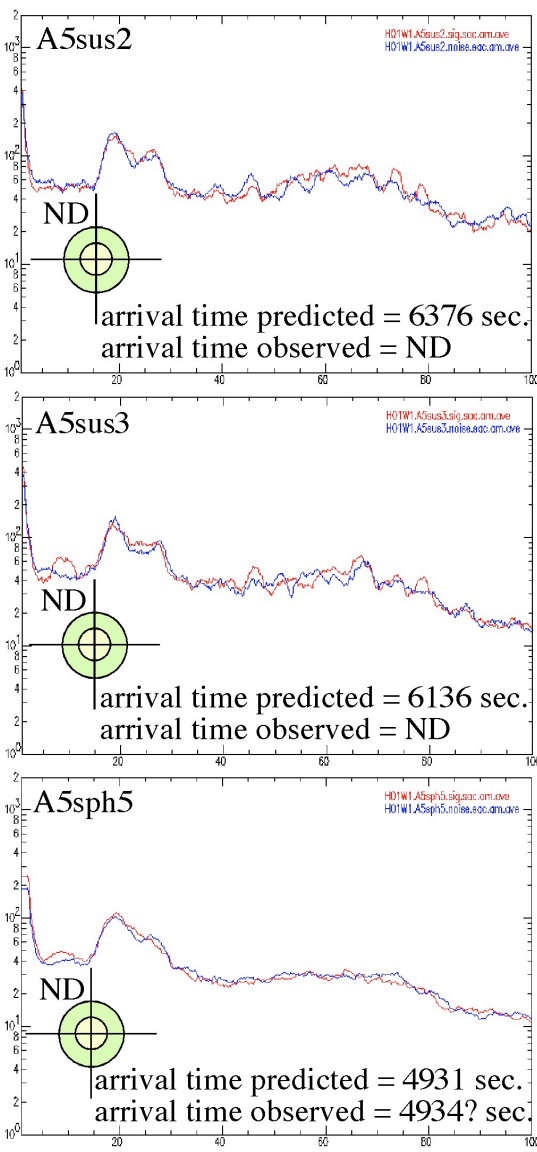

Diego Garcia South
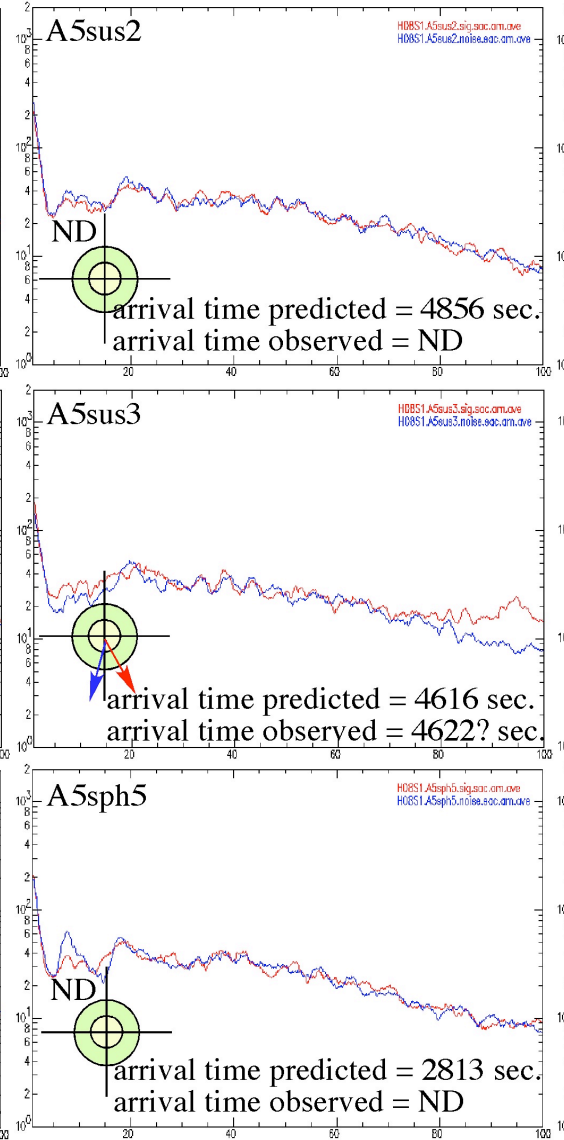

Diego Garcia North
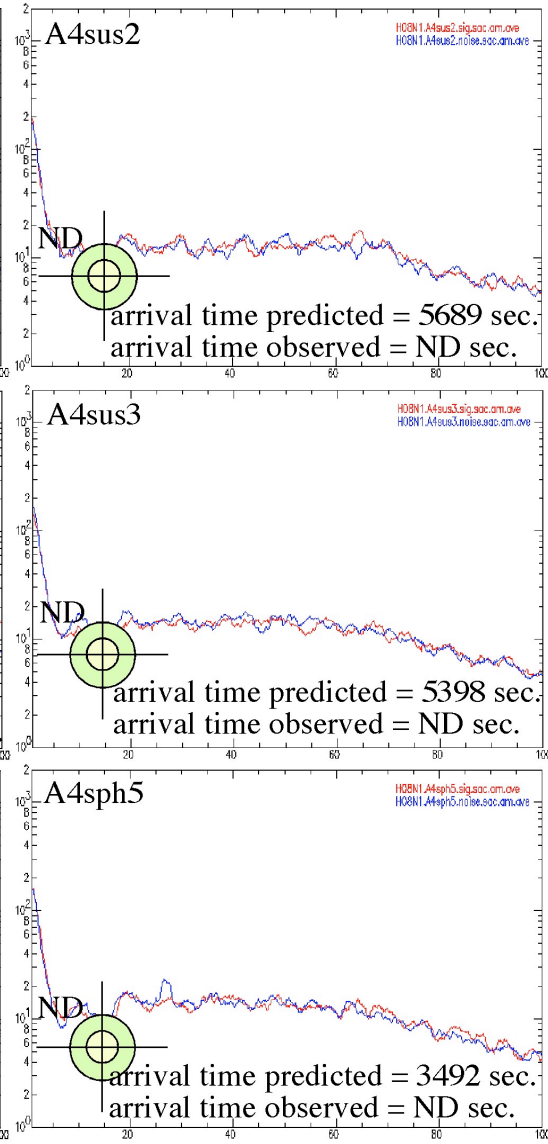

Figure B5. Spectra for sources at site A5. The sources consisted of a $1.8 \mathrm{lb}$ SUS charge at $610 \mathrm{~m}$ depth (top row) and a $1.8 \mathrm{lb}$ SUS charge at $915 \mathrm{~m}$ depth (middle row), and a five-sphere glass implosion at $726 \mathrm{~m}$ depth (bottom row).
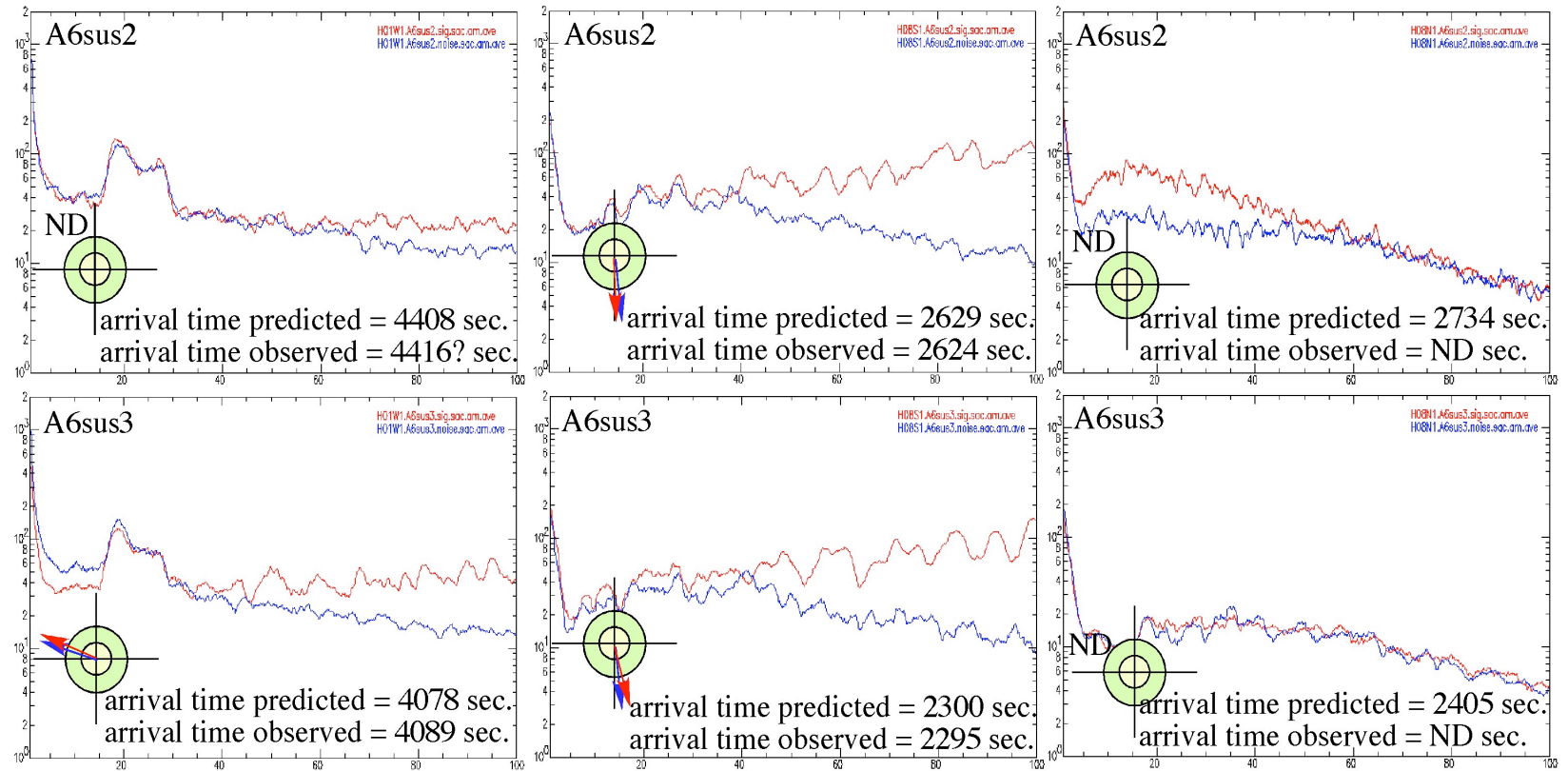

Figure B6. Spectra for sources at site A6. The source consisted of a $1.8 \mathrm{lb}$ SUS charge at $610 \mathrm{~m}$ depth (top row) and a $1.8 \mathrm{lb}$ SUS charge at $915 \mathrm{~m}$ depth (bottom row). 
Cape Leeuwin
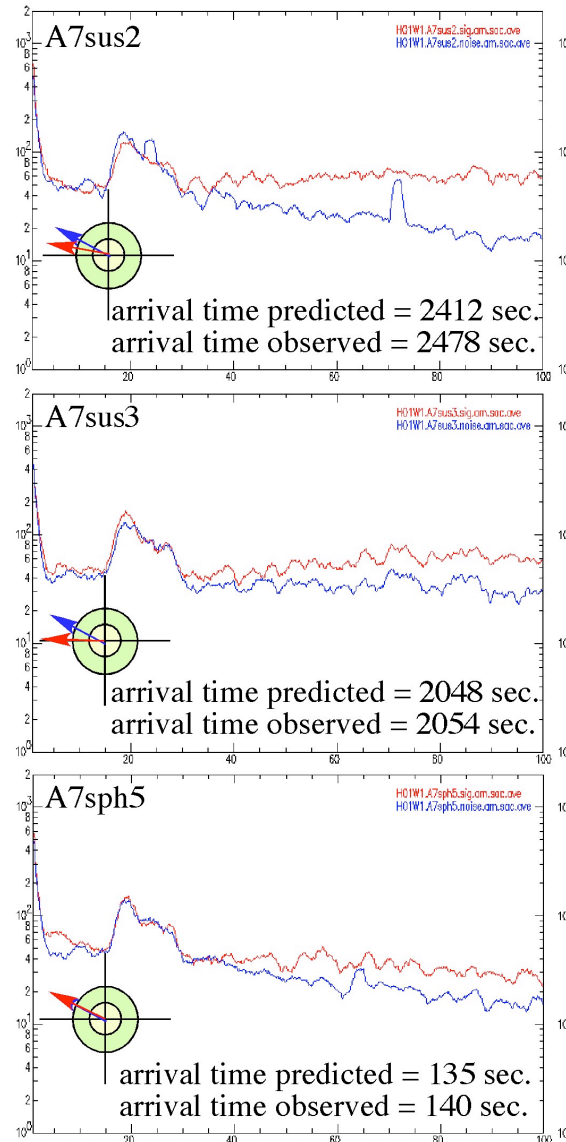

Diego Garcia South
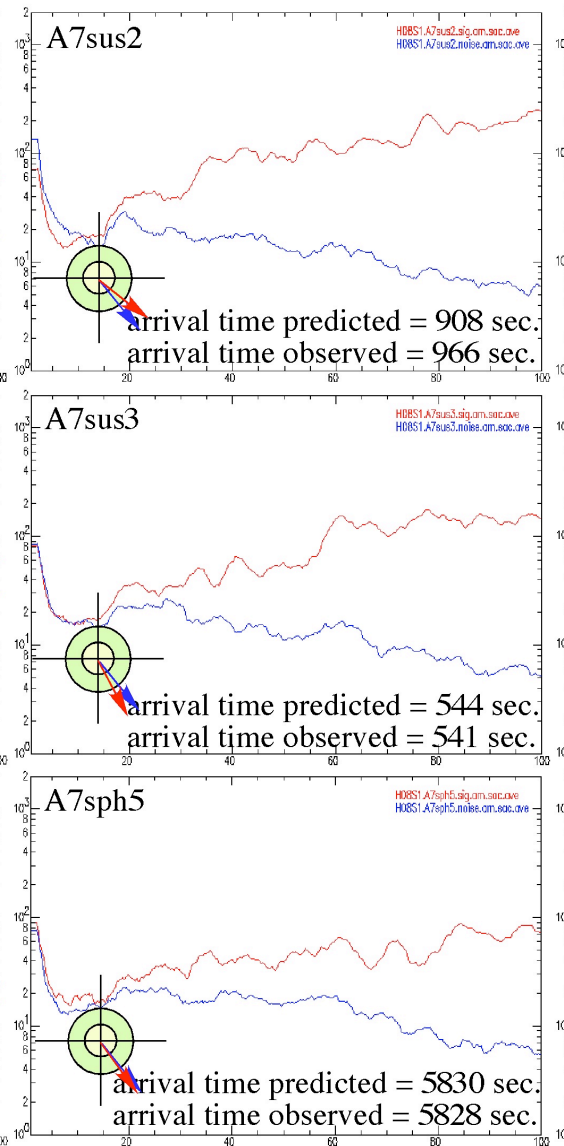

Diego Garcia North
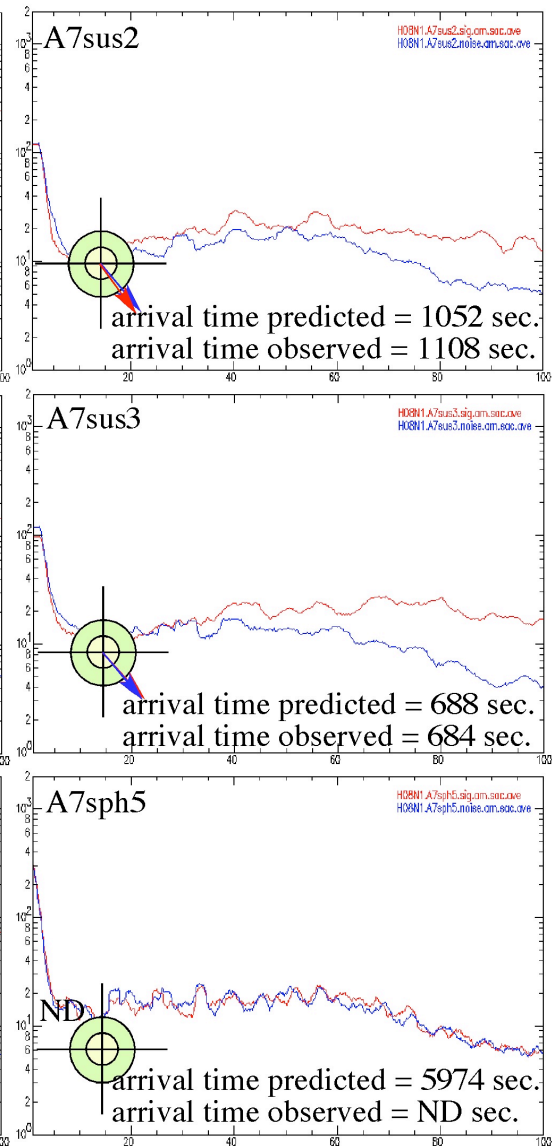

Figure B7. Spectra for sources at site A7. The sources consisted of a $1.8 \mathrm{lb}$ SUS charge at $610 \mathrm{~m}$ depth (top row) and a $1.8 \mathrm{lb}$ SUS charge at $915 \mathrm{~m}$ depth (middle row), and a 5-sphere glass implosion at $713 \mathrm{~m}$ depth (bottom row). 
Cape Leeuwin

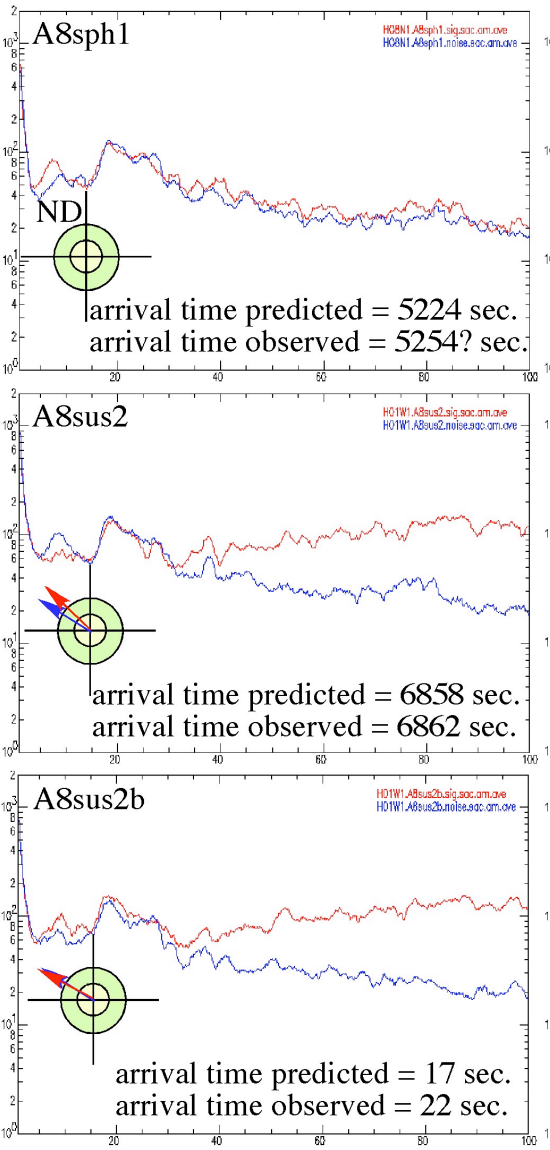

Diego Garcia South
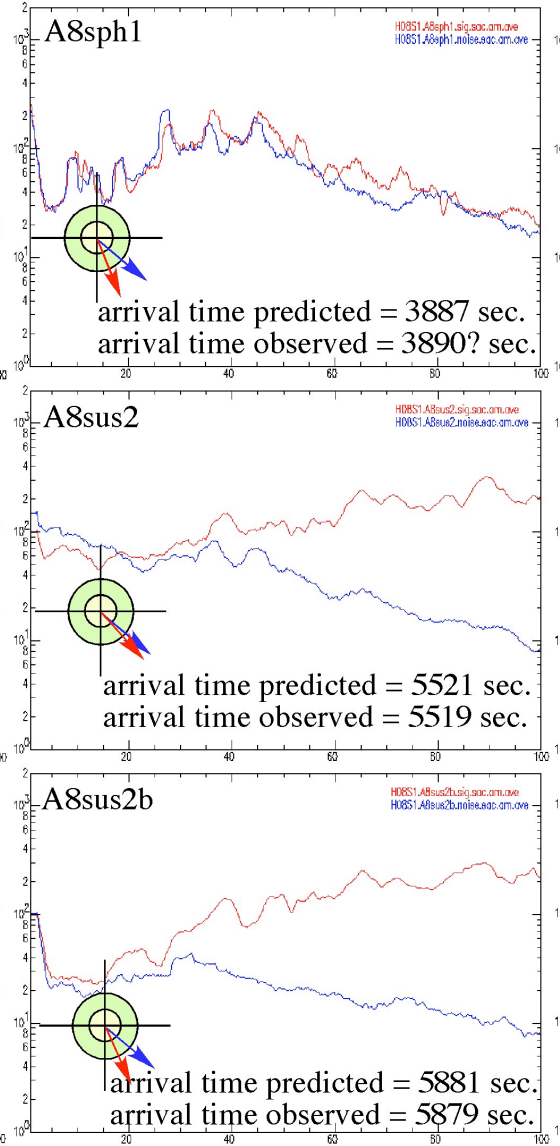

Diego Garcia North
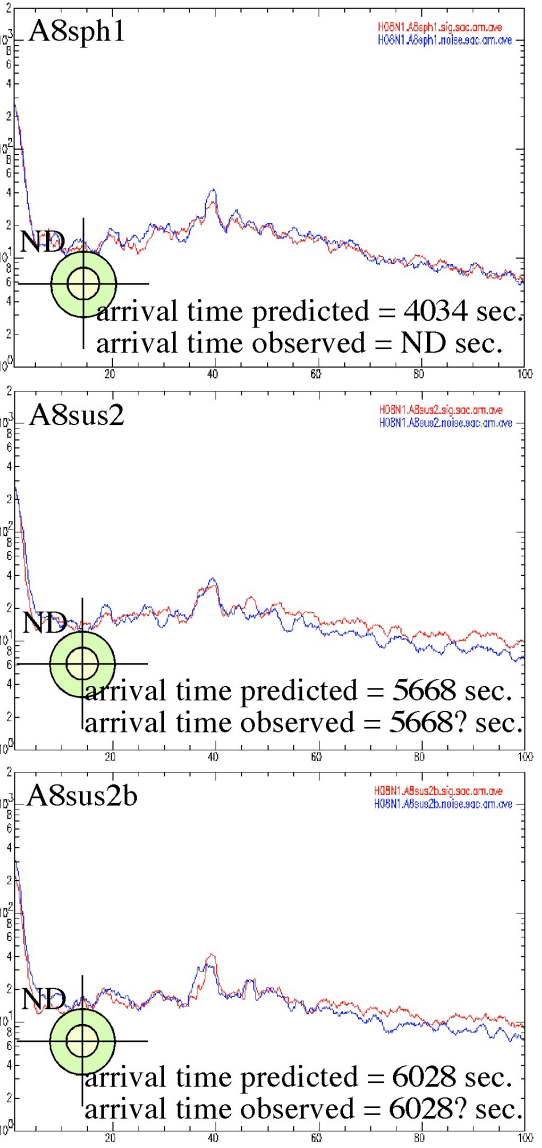

Figure B8. Spectra for sources at site A8. The sources consisted of a single-sphere glass implosion at $725 \mathrm{~m}$ depth (top row), a $1.8 \mathrm{lb}$ SUS charge at $610 \mathrm{~m}$ depth (middle row) and a $1.8 \mathrm{lb}$ SUS charge at $915 \mathrm{~m}$ depth (bottom row).
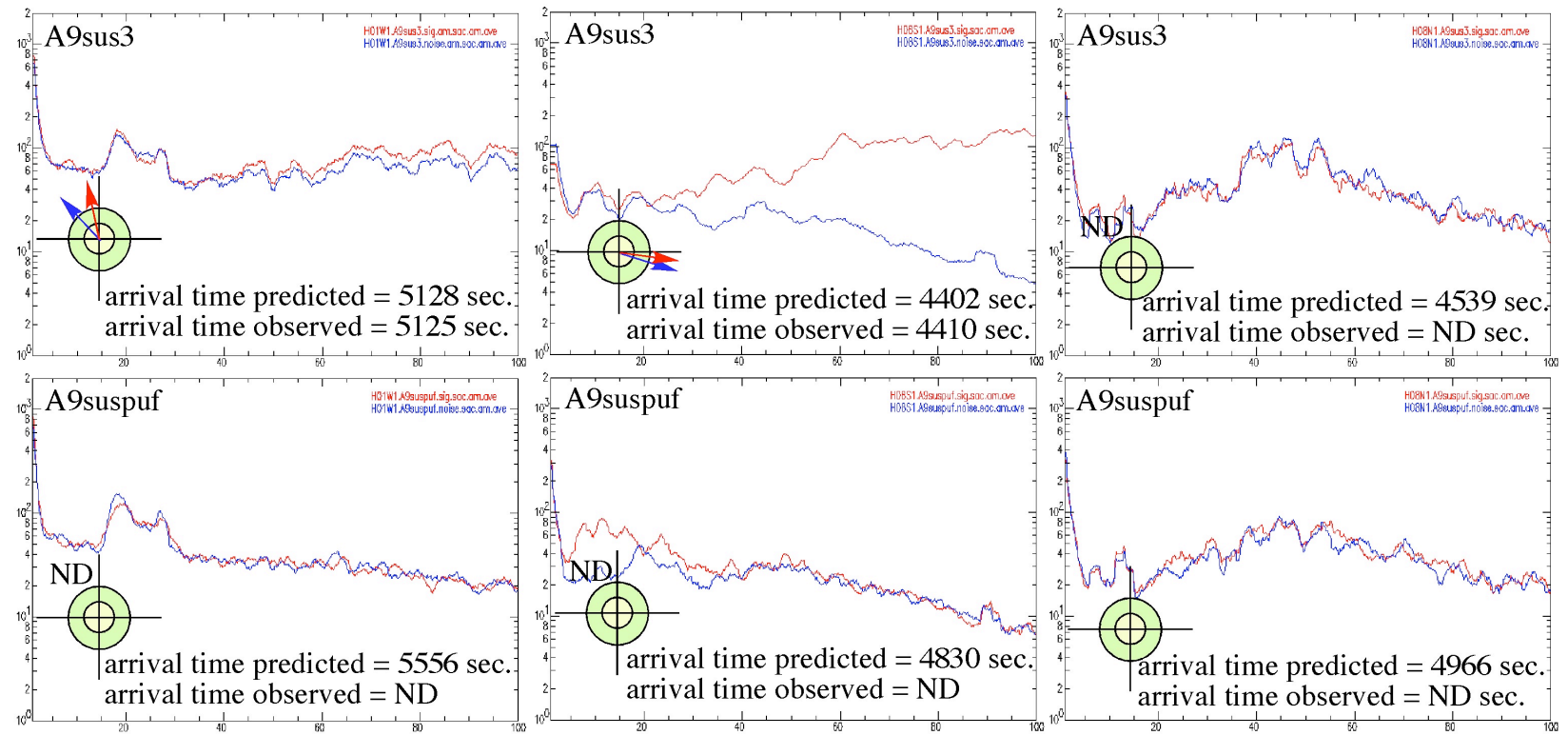

Figure B9. Spectra for sources at site A9. The sources consisted of a $1.8 \mathrm{lb}$ SUS charge at $915 \mathrm{~m}$ depth (top row) and a $1.8 \mathrm{lb}$ SUS charge at $<610 \mathrm{~m}$ depth where only the trigger charge ignited, not the full charge (bottom row). 
Cape Leeuwin
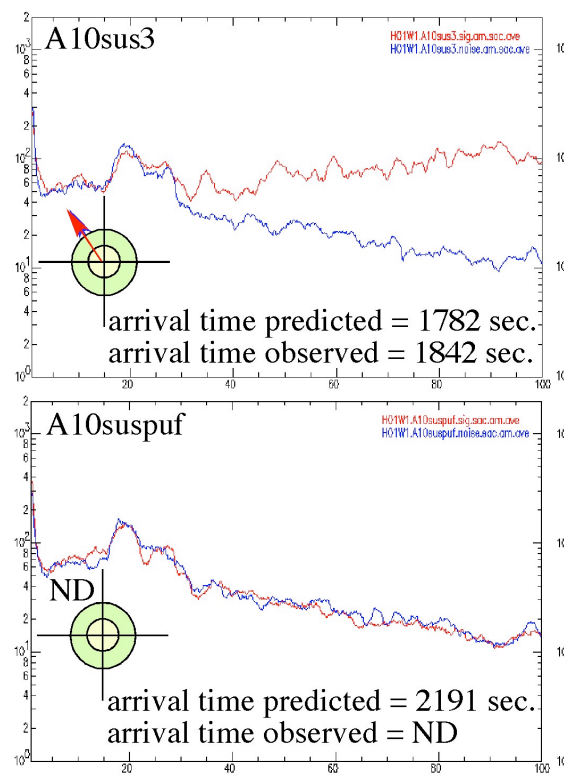

Diego Garcia South
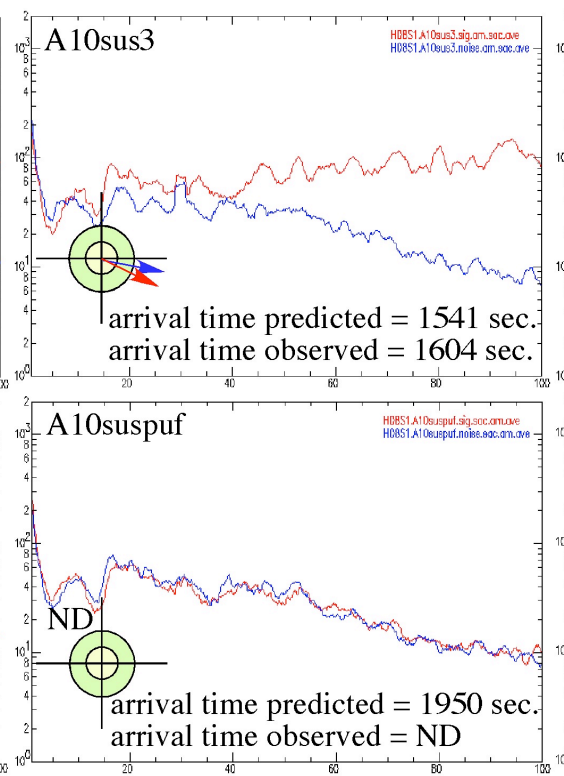

Diego Garcia North
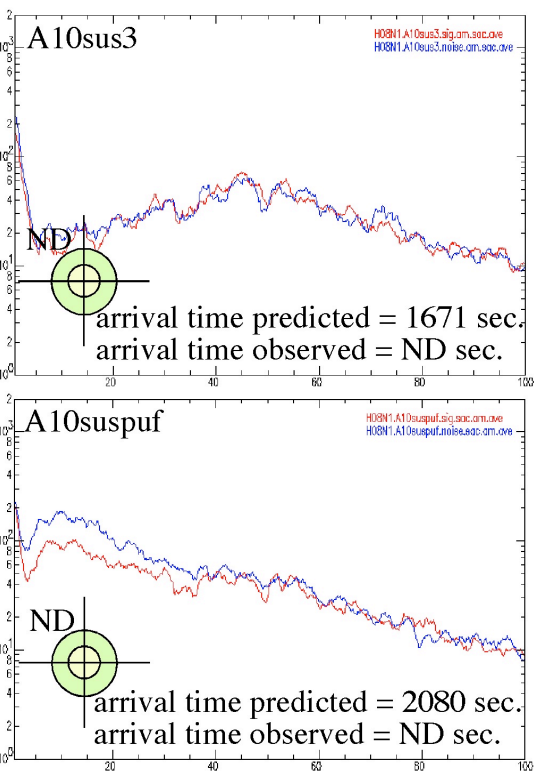

Figure B10. Spectra for sources at site A10. The sources consisted of a $1.8 \mathrm{lb}$ SUS charge at $915 \mathrm{~m}$ depth (top row) and a $1.8 \mathrm{lb}$ SUS charge at $610 \mathrm{~m}$ depth where the charge did not fully fire (bottom row).

Cape Leeuwin
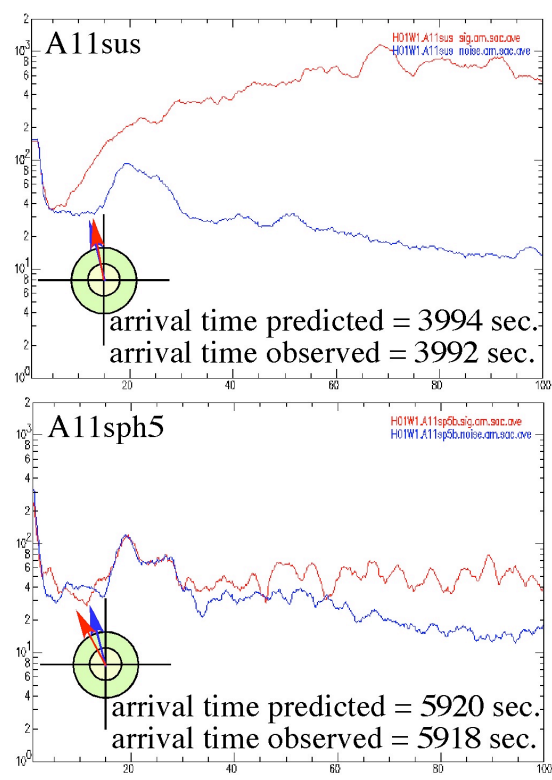

Diego Garcia South
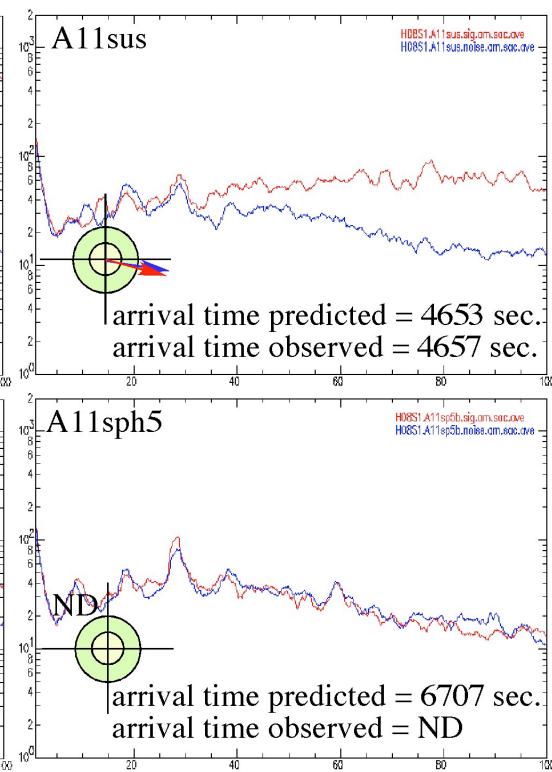

Diego Garcia North
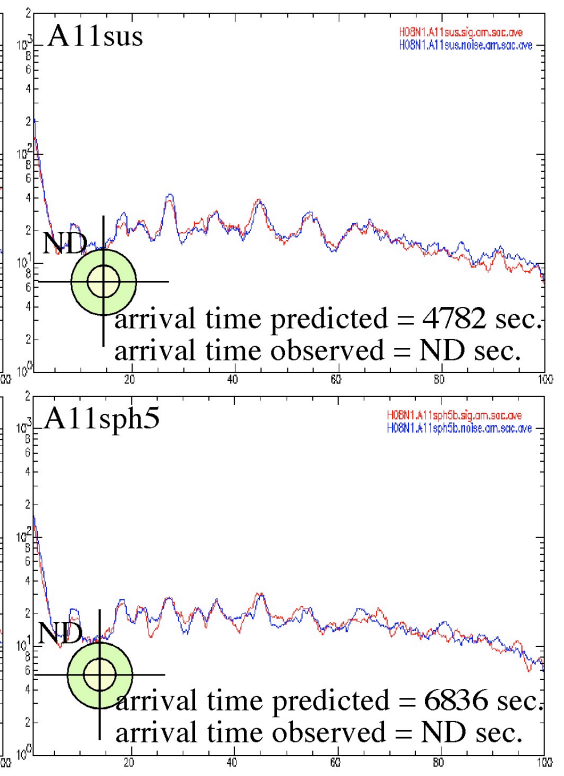

Figure B11. Spectra for sources at site A11. The sources consisted of a SUS charge at $915 \mathrm{~m}$ depth (top row) and a five-sphere glass implosion at $731 \mathrm{~m}$ depth (bottom row). 


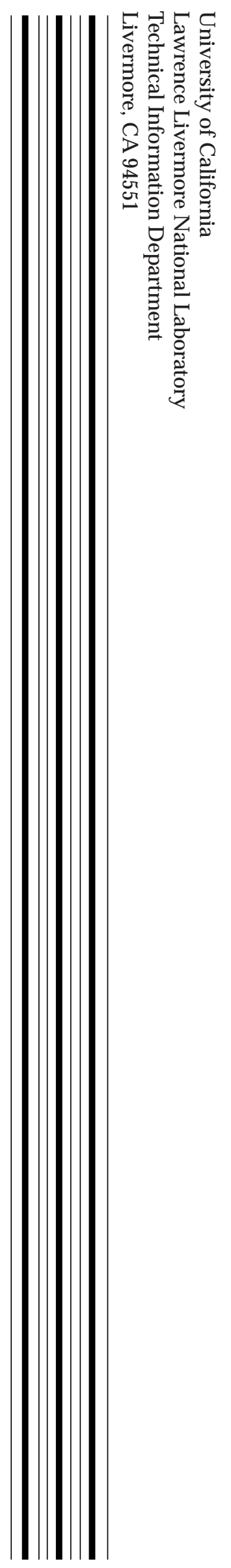

